\title{
Heterogeneous Responses to Effective Tax Enforcement: Evidence from Spanish Firms*
}

\author{
Miguel Almunia \\ University of Warwick \\ David Lopez-Rodriguez \\ Banco de España
}

July 18, 2014

\begin{abstract}
We investigate whether monitoring the information trails generated by firms' activities improves tax compliance. We exploit quasi-experimental variation generated by a Large Taxpayers' Unit (LTU) in Spain, which devotes additional resources to verifying the transactions reported by firms with more than $€ 6$ million in reported revenue. Firms bunch below this threshold in order to avoid stricter tax enforcement, and this reaction is stronger in sectors where paper trail is easier to monitor. These results suggest that monitoring efforts by the tax authority and the traceability of information reported by firms are complements, and both are necessary for effective tax enforcement.

Keywords: tax enforcement, firms, bunching, Spain, Large Taxpayers Unit (LTU). JEL codes: H26, H32.
\end{abstract}

\footnotetext{
*Almunia (corresponding author): m.almunia@warwick.ac.uk, University of Warwick Department of Economics and Centre for Competitive Advantage in the Global Economy (CAGE). Lopez-Rodriguez: david.lopezr@bde.es, Banco de España. We thank Emmanuel Saez, Alan Auerbach, Fred Finan and Ted Miguel for constant support and encouragement throughout this project. We gratefully acknowledge many useful comments and suggestions from Juan Pablo Atal, Henrique Basso, Michael Best, David Card, Lorenzo Casaburi, Raj Chetty, Francisco de la Torre, François Gerard, Jonas Hjort, Simon Jäger, Attila Lindner, Justin McCrary, Craig McIntosh, Adair Morse, Gautam Rao, Ana Rocca, Michel Serafinelli, Monica Singhal, Juan Carlos Suárez Serrato, Victoria Vanasco, Andrea Weber, Danny Yagan, Owen Zidar and numerous seminar participants. Almunia gratefully acknowledges financial support from Fundación Rafael del Pino and the Burch Center for Tax Policy and Public Finance. Any views expressed in this paper are only those of the authors and should not be attributed to the Banco de España.
} 


\section{Introduction}

Modern tax systems in advanced economies feature high levels of tax compliance despite low audit rates, an outcome at odds with the predictions of the classical deterrence model of tax evasion (Allingham and Sandmo, 1972). More recent theoretical studies argue that third-party information reporting is critical to reconcile these two facts because of its additional deterrence effect on taxpayers (Kopczuk and Slemrod, 2006; Kleven, Kreiner and Saez, 2009; Gordon and Li, 2009). Indeed, experimental evidence shows that individual income tax compliance is much higher when the tax authority has the capacity to match tax returns and third-party information reports in a systematic way (Slemrod, Blumenthal and Christian, 2001; Kleven et al., 2011). Even though firms produce the majority of these reports and they remit ${ }^{1}$ most of the tax payments collected by governments, empirical studies of tax compliance usually focus on individuals, rather than analyzing firm behavior.

This paper contributes to fill this gap by analyzing whether the existence of thirdparty reporting is sufficient to ensure high tax compliance by firms. First, we derive theoretical predictions on how firms respond to higher tax enforcement intensity, which results from the more effective use of the information trails created by firms' activities through various channels. These predictions are then tested using quasi-experimental variation provided by the Large Taxpayers Unit (LTU) in Spain. ${ }^{2}$ The Spanish LTU, a special unit within the tax authority, devotes additional monetary and human resources to verify tax returns (e.g., audits) and monitor activities of firms with more than $€ 6$ million in annual operating revenue. The monitoring intensity changes discretely at this arbitrary revenue threshold, while firms just below and above face the same tax schedule and information requirements. This allows us to study the effect of stricter tax enforcement on firms' compliance behavior.

In our baseline theoretical framework, firms with heterogeneous productivities make their production and tax reporting decisions to maximize expected profits, for a given tax rate on reported profits. There is an incentive to misreport revenue because it lowers tax liability, but to do so firms incur some resource costs (e.g., keeping two sets of accounting books or foregoing business opportunities). The deterrence component of tax compliance is captured by a detection probability that increases endogenously with the amount

\footnotetext{
${ }^{1}$ For instance, in the United States firms remit $84 \%$ of all taxes collected by the federal government (Christensen, Cline and Neubig, 2001). As taxpayers, they remit corporate income tax and a share of payroll tax. As tax collectors, they withhold income and payroll tax from employees. In other advanced countries, firms also remit value added tax (VAT) payments.

${ }^{2}$ Many tax authorities in advanced countries, and an increasing number of emerging countries, have some type of LTU to deal with large businesses (IMF, 2002; OECD, 2011). Firms in the Spanish LTU represent $2.5 \%$ of all registered businesses, employ $40 \%$ of private sector workers and report $80 \%$ of taxable profits (AEAT, 1999-2008).
} 
evaded by firms. This probability results from the interaction between (i) the resources devoted by the tax authority to monitor firms ("monitoring effort"); and (ii) the existing enforcement technology to analyze tax returns and systematically check them against other information generated by business transactions. We introduce a notch in tax enforcement intensity by assuming that monitoring effort jumps up discretely at a fixed level of reported revenue, while reporting requirements and the enforcement technology remain constant. The increase in monitoring resources above the threshold strengthens the effectiveness of the enforcement technology, leading firms to bunch below the LTU threshold in order to avoid more effective tax enforcement. Absent prohibitive resource costs, the bunching response creates a "hole" in the distribution of reported revenue with zero mass in an interval above the tax enforcement notch. We discuss below an extended model where resource costs of evasion may prevent the reaction to the threshold.

In the empirical analysis, we use financial statements and balance-sheet data reported by Spanish firms to the Commercial Registry. This dataset, compiled at the European level by Amadeus, contains firm-level information on annual operating revenue, input expenditures, fixed assets and number of employees, making it possible to analyze multiple margins of firms' responses to the tax enforcement threshold. In addition, the longitudinal structure of the dataset allows us to analyze the dynamic behavior of firms. The dataset covers more than $80 \%$ of registered businesses in Spain with operating revenue in the $€ 3$-€9 million range for the period 1999-2007, during which the LTU threshold remained constant at $€ 6$ million.

The first set of results shows a considerable reaction to avoid the stricter monitoring effort by the tax agency. Consistent with the predicted response to more effective tax enforcement, we find substantial bunching of firms just below the LTU threshold in the empirical distribution of reported revenue. Adopting the empirical procedure developed in Kleven and Waseem (2013), we quantify the effect of larger tax enforcement on firms' reported revenue by comparing the observed and the counterfactual revenue density around the threshold. Estimates indicate that, on average, bunching firms reduce their reported revenue by $€ 101,000$ (about $1.7 \%$ of total revenue) to stay under lower monitoring effort. Considering that high resource costs of evasion prevent some firms from responding, the adjusted estimates show that the marginal bunching firm reduces reported revenue by about $€ 593,000$ (almost 10\% of total revenue). Both estimates are statistically significant at the $1 \%$ level. Robustness checks indicate that the bunching response is neither due to other size-contingent regulations nor caused by the persistence of a small group of firms just below the threshold. Moreover, the estimates are robust to different assumptions when estimating the counterfactual distribution.

The second set of results illustrates the role of deterrence and resource costs on the tax 
compliance behavior of firms. We extend the baseline model along two dimensions to allow for heterogeneous responses across different firm characteristics: the traceability of firms' transactions and the resource costs related to evasion. In the first extension, we consider how the position in the production chain affects the traceability of a firm's transactions. When a firm sells intermediate inputs, transactions generate substantial information trails so it is easier for the tax agency to detect evasion by matching tax returns to other information sources. In contrast, sales to final consumers tend to leave little or no paper trail, so even an exhaustive audit by the LTU may be unable to detect evasion. Hence, variation in the traceability of transactions implies that the same monitoring effort results in different effective enforcement intensities for each firm, holding revenue fixed. We test this hypothesis empirically dividing the data into ten sectors of activity. We find that the bunching response is strongest in sectors that sell mostly intermediate inputs (e.g., wholesalers, heavy manufacturers) and much weaker in sectors that sell mostly to final consumers (e.g., retailers, restaurants and hotels). This result indicates that the effectiveness of additional monitoring effort depends crucially on the traceability of firms' transactions. In terms of our theoretical framework, this finding suggests that information reporting requirements and monitoring resources are complements, because it is the interaction between the two that deters firms from evading taxes.

In the second extension, we allow for variation in the resource costs of evasion. These costs reduce the profitability of tax evasion and hence lower the incentives to misreport revenue (regardless of monitoring effort). In some cases, resource costs may be so high that firms do not misreport their revenue at all. This could be due to the complexity of firms' operations, which makes tax evasion unfeasible because it is too costly compared to the expected benefits (Kleven, Kreiner and Saez, 2009). The presence of such prohibitive resource costs of evasion for a significant proportion of firms not only attenuates the bunching response, but it also helps explain why we observe only a small dip, rather than a hole, in the distribution of revenue just above the LTU threshold. To complement this analysis, we divide the sample using proxies for the complexity of firms' operations. We find that bunching is lower, but still significant, among firms with more employees and a larger stock of fixed assets, confirming the intuition that complexity of operations affects the relevance of resource costs.

The third set of results analyzes the mechanisms behind firms' responses to avoid more effective tax enforcement. To do this, we consider a model in which firms may also misreport their input expenditures. Firms have incentives to overreport their materials (to lower their VAT and corporate income tax liabilities) and underreport labor expenditures (to lower their payroll tax liabilities). ${ }^{3}$ The model's predictions depend on whether the

\footnotetext{
${ }^{3}$ Underreporting labor expenditures increases corporate tax liabilities, but this can be compensated
} 
bunching response is due to real (i.e. lower output) or evasion (i.e. increase of concealed revenue) adjustments. We assess the plausibility of each type of response using a simple graphical test where the outcomes are the reported ratios of input expenditures over revenue. We find that the average ratio of material expenditures for firms just below the LTU threshold is $66 \%$, but the ratio shifts down to $64 \%$ for firms just above. In contrast, average labor expenditures shift up from $15 \%$ below threshold to $16 \%$ above. According to our theoretical predictions, these empirical patterns are not compatible with a real response, which would have resulted in upward shifts of both inputs at the threshold (because bunching firms are more productive). Instead, the evidence is fully consistent with an evasion response in which bunching firms strategically misreport their expenditures to maximize tax evasion. ${ }^{4}$ While we cannot infer causality from these patterns, they provide suggestive evidence that firms are able to misreport their input expenditures when they are under low monitoring effort, even in the presence of third-party reporting.

The findings in this paper contribute to the thin empirical literature on business tax evasion by providing a well-identified measure of the effects of tax enforcement on firm behavior in an advanced economy. De Paula and Scheinkman (2010) and Pomeranz (2013) emphasize the key role of information for effective tax enforcement, particularly through the self-enforcing mechanisms of the VAT. ${ }^{5}$ In an experiment with small Chilean firms, Pomeranz (2013) finds that the VAT paper trail acts as a substitute of tax audits to improve tax compliance. In contrast, our results suggest that additional resources to perform audits and the existence of information trails are complements and that both are necessary to increase tax compliance by firms. Showing another limitation of third-party reporting, Carrillo, Singhal and Pomeranz (2014) find that firms in Ecuador respond to the use of third-party reported information by substituting evasion into less verifiable margins, such as input expenditures. We also contribute by providing evidence on the importance of resource costs of evasion, related with firms' size and complexity (as discussed in Kleven, Kreiner and Saez, 2009).

The empirical techniques used in this paper draw on a growing literature in public finance that analyzes agents' responses to thresholds in taxes and regulations. In the seminal paper of this literature, Saez (2010) exploits kinks - i.e., income thresholds

by the tax savings on the payroll tax. During the period under study, the statutory payroll tax in Spain was $38 \%$ (including both the employer's and the employee's shares), compared to a corporate income tax rate that declined from $35 \%$ to $30 \%$. Moreover, keeping reported salaries low and paying part under the table protects firms against future negative shocks, because there is downward nominal wage rigidity.

${ }^{4}$ Disaggregating labor expenditures, we find evidence on wage misreporting with a downward jump of average wages for firms just below the threshold, while the average number of employees is similar around it. There is additional theoretical support for labor misreporting in Yaniv (1988), and pervasive evidence of salary underreporting in many countries, as shown in recent empirical studies such as Kumler, Verhoogen and Frias (2012) and Best (2013), and even in the US (Slemrod and Gillitzer, 2014).

${ }^{5}$ In fiscal systems with a VAT, the transmission of evasion (or compliance) behavior moves upwards the production chain from retailers to intermediate goods suppliers. 
at which the marginal tax rate jumps - to identify taxable income elasticities. ${ }^{6}$ Our estimation strategy is most closely-related to Kleven and Waseem (2013), who exploit notches - income thresholds at which the average tax rate jumps. ${ }^{7}$ The novel feature of our setting is that the Spanish LTU generates a notch in enforcement intensity, rather than the tax rate, allowing us to study the effects of tax enforcement policies in isolation.

Finally, our paper contributes to an extensive literature on the effects of size-dependent policies and regulations on firm behavior. One strand of this literature has focused on the impact of such regulations on productivity, given the pervasive incentives for firms to remain inefficiently small (Guner, Ventura and Xu, 2008; Restuccia and Rogerson, 2008; Garicano, LeLarge and van Reenen, 2013). Other studies have instead focused on evasion and avoidance responses. For instance, Onji (2009) shows that Japanese firms reacted to the introduction of a VAT eligibility threshold by splitting into several smaller entities in other to avoid taxation. In a similar vein, our results show that some firms may look smaller in the data than they are in reality because of misreporting under low tax enforcement, which could have important implications for productivity estimations in many contexts.

The rest of the paper is organized as follows. Section 2 presents the theoretical framework. Section 3 describes the empirical strategy and derives the bunching estimators. Section 4 provides institutional context and describes the data. Section 5 presents the estimation results. Section 6 concludes.

\section{Theoretical Framework}

We model the problem of profit-maximizing firms that can evade taxes and face the risk of being detected (and punished) by the tax authority. In the basic setting, firms make production decisions and are able to misreport their revenue, but they bear resource costs associated to tax evasion. The probability of detection depends on the tax authority's monitoring efforts and the available technology to cross-check tax returns to find inconsistencies in reporting, taking advantage of the paper trail generated by information requirements. This probability therefore depends endogenously on each firm's level of evasion. We use this framework to examine how firms respond to a discontinuity in tax enforcement intensity generated by a sharp increase in monitoring efforts at an arbitrary

\footnotetext{
${ }^{6} \mathrm{~A}$ number of recent studies apply Saez's method to derive taxable income elasticities using large administrative datasets from Denmark, Sweden and the United States (Chetty et al., 2011; Bastani and Selin, 2014; Chetty, Friedman and Saez, 2013). Devereux, Liu and Loretz (2014) also use bunching techniques to estimate the elasticity of corporate taxable income in the United Kingdom.

${ }^{7}$ Slemrod (2010) provides a general description of notches in tax and regulatory systems. Two recent working papers, Best and Kleven (2013) and Kopczuk and Munroe (forthcoming) study notches generated by property transaction taxes.
} 
revenue threshold. We then extend the model to allow for heterogeneity across firms in the resource costs of evasion and in the effective monitoring intensity, which yields testable predictions about the shape of the distribution of reported revenue.

\subsection{Corporate Taxation with Risky Evasion}

Consider an economy with a continuum of firms of measure one whose income is taxed by the government. Firms produce good $y$ combining tax-deductible inputs $x$ and nondeductible inputs $z$ according to the production function $y=\psi f(x, z)$, where $\psi$ is a productivity parameter and $f(\cdot, \cdot)$ is strictly continuous, increasing and concave in both arguments. Productivity $\psi$ is exogenously distributed over the range $[\underline{\psi}, \bar{\psi}]$ with a smoothly decreasing and convex density $d_{0}(\psi)$ in the population of firms. Firms purchase deductible and nondeductible inputs in competitive markets at unit cost $w$ and $q$, respectively, and sell their output at the market price $p$, which is normalized to unity.

The government levies a proportional tax $t$ on taxable profits $P=y-w x$, so net-oftax profits with truthful reporting are given by $\Pi=(1-t) P-q z$. Since the tax authority does not perfectly observe all transactions in the economy, firms may attempt to evade taxes by misreporting taxable profits. In the baseline case, firms can underreport their revenue by an amount $u \equiv y-\bar{y} \geq 0$, where $\bar{y}$ is reported revenue ${ }^{8}$ and, therefore, reported taxable profits are given by $\bar{P}=(1-t)[\bar{y}-w x]$. The direct and indirect resource costs of evasion are captured with the reduced form $\kappa(u)$, which is an increasing and convex function of concealed revenue. ${ }^{9}$

The tax authority detects evasion with probability $\delta=\phi h(u)$, where $\phi>0$ is an enforcement intensity parameter, and $h(\cdot)$ is a continuous, increasing and convex function in concealed revenue. Enforcement intensity $\phi$ measures the monitoring effort exerted by the tax authority, which depends on the resources devoted toe examine firms' tax returns and undertake tax audits. The endogenous component, $h(u)$, represents the technology used to match tax returns among trading partners and to review the paper trail created by information-reporting requirements. This component captures the intuition that a larger amount of unreported sales increases the probability of detection because each inconsistency in reported transactions leaves a paper trail that can be examined (e.g. discrepancies in the monetary value of sales reported by firms and the purchases claimed as tax credits by their clients). Hence, the detection probability is determined by the

\footnotetext{
${ }^{8}$ In subsection 5.4, we discuss the predictions of an extended model in which firms can also evade taxes by misreporting their input costs. We fully derive the extended model in the online appendix.

${ }^{9}$ One example of these resource costs of evasion is the need to maintain parallel accounting books to keep track of black payments in cash. Tax evading firms may also forego business opportunities by not accepting credit cards or bank payments, given that it is much easier to conceal cash transactions. See Chetty (2009) for a detailed discussion on the economic nature of these resource costs.
} 
interaction between the resources devoted to monitoring $\phi$ and the enforcement technology $h(u)$. Intuitively, these two elements are complementary and both are necessary to achieve effective tax enforcement. For simplicity, we assume that when discrepancies between firms' reported transactions are detected, the authorities uncover the full amount evaded. Whenever evasion is detected, the tax authority imposes a fine with a penalty rate $\theta$ over the amount of tax evaded, on top of the true tax liability. ${ }^{10}$

Firms make production (i.e., demand of inputs $x$ and $z$ ) and reporting (i.e., underreported revenue $u$ ) decisions in order to maximize expected after-tax profit, given by

$$
\mathbb{E} \Pi=(1-t)[\psi f(x, z)-w x]-q z-\kappa(u)+t u[1-\phi h(u)(1+\theta)] .
$$

An interior optimum satisfies the following system of first-order conditions: ${ }^{11}$

$$
\begin{aligned}
\psi f_{x}(x, z) & =w \\
\psi f_{z}(x, z) & =q /(1-t) \\
t[1-\phi h(u)(1+\theta)] & =\kappa_{u}(u)+t u(1+\theta) \phi h_{u}(u)
\end{aligned}
$$

where the term $[1-\phi h(u)(1+\theta)] \equiv r$ is the expected rate of return of evasion. This system of equations indicates that a positive tax rate has two effects. First, it distorts the choice of inputs, reducing production below the zero-tax optimum. Second, it creates incentives to evade taxes, thereby reducing reported revenue for all firms in equilibrium. Simple comparative statics show that an increase in enforcement intensity $\phi$ leads to a decrease in concealed revenue $u$.

To provide more intuition on firms' incentives to evade taxes, we define the elasticity of detection probability with respect to concealed income as $\varepsilon_{\delta, u} \equiv \phi h_{u} \cdot u / \delta$, and rewrite the optimal evasion condition (4) as follows ${ }^{12}$

$$
1=\frac{\kappa_{u}(u)}{t}+(1+\theta) \delta(u)\left[1+\varepsilon_{\delta, u}\right]
$$

The right-hand side of (5) identifies the two mechanisms that contribute to raising tax compliance by firms. The first term shows the disincentive effect created by the presence of marginal resource costs (relative to the marginal benefit of evasion, i.e., the tax rate). The second term represents the deterrence effect generated by the interaction between

\footnotetext{
${ }^{10}$ The canonical Allingham and Sandmo (1972) model of income tax evasion assumes that the penalty applies to the total amount evaded, but Yitzhaki (1974) points out that the common practice in most countries is to make the penalty proportional to the amount of tax evaded.

${ }^{11}$ The assumption of convex detection probability is sufficient to ensure the second-order condition for interior optimum is satisfied.

${ }^{12}$ This equation is similar to the one derived by Kleven et al. (2011), but obtained from the choice problem of firms, with an additional term to capture the impact of resource costs of evasion.
} 
the tax authority's monitoring effort and the existence of a paper trail generated by misreporting behavior.

Given that the production and resource cost functions, $f(\cdot)$ and $\kappa(\cdot)$, are homogeneous among firms, all the variation in reported revenue $\bar{y}$ is due to differences in productivity $\psi$ across firms. For a constant monitoring effort $\phi$, there exists a density function of reported revenue $g_{0}(\bar{y})$ which is smoothly decreasing and convex in its full domain $\left[\bar{y}_{\min }(\underline{\psi}), \bar{y}_{\max }(\bar{\psi})\right]{ }^{13}$ Hence, the observed distribution of reported revenue is smoothly decreasing and convex in firms' productivity. This theoretical distribution is depicted by the black dashed line in Figure 1.

\section{Large Taxpayers Unit (LTU): A Tax Enforcement Notch}

Assume now that the government provides additional resources to the tax authority in order to create a Large Taxpayers Unit (LTU). The LTU increases the monitoring effort from $\phi_{0}$ to $\phi_{1}=\phi_{0}+d \phi$ (where $d \phi>0$ ) only for firms with reported revenue $\bar{y}>y^{L}$, where $y^{L}$ denotes the threshold for LTU eligibility. Notice that this reform raises the monitoring effort without affecting the technology used to match tax returns or the information-reporting requirements that generate paper trails, $h(u)$. We can now express the probability of detection as

$$
\delta=\left[\phi_{0}+d \phi \cdot \mathbf{1}\left(\bar{y}>y^{L}\right)\right] \cdot h(u)
$$

where $\mathbf{1}(\cdot)$ is an indicator for being above the LTU threshold. The introduction of the LTU creates a tax enforcement notch, meaning that monitoring intensity (and, consequently, the probability of detection) increases discretely at the arbitrary revenue level $y^{L}$.

The predicted reaction of firms to the tax enforcement notch allows us to classify them in three groups depending on their exogenous productivity draw. First, consider a firm with productivity $\psi^{L}$ such that its optimal pre-LTU reported revenue is exactly the enforcement threshold, $y^{L}$. This firm determines the upper bound of the "low productivity" group of firms with $\psi \in\left[\underline{\psi}, \psi^{L}\right]$ that are not LTU-eligible, and thus their production and reporting decisions remain unaffected by this reform. Second, consider a firm with productivity $\psi^{M}$, such that its pre-LTU reported revenue is $y^{M}>y^{L}$. This firm is indifferent between being monitored by the LTU and bunching at the threshold to avoid becoming eligible, because its expected profits are equal in both cases, that is

$$
\mathbb{E} \Pi_{0}\left(x, z, u \mid \phi_{0}, \psi^{M}\right)=\mathbb{E} \Pi_{1}\left(x^{\prime}, z^{\prime}, u^{\prime} \mid \phi_{1}, \psi^{M}\right) .
$$

\footnotetext{
${ }^{13}$ The specific mapping between the productivity and reported revenue density functions depends on the functional forms of the production function $f(\cdot)$ and the enforcement technology $\delta=\phi h(u)$.
} 
We denote this firm as the "marginal buncher", i.e., the firm with the highest productivity that bunches at the threshold. Hence, the group of firms with $\psi \in\left(\psi^{L}, \psi^{M}\right]$ are the bunchers that react to the introduction of a LTU by reporting lower revenue in order to locate exactly at the LTU threshold. Third, we consider the group of "high productivity" firms with $\psi \in\left[\psi^{M}, \bar{\psi}\right.$. These firms become LTU-eligible but it is too costly for them to reduce their reported revenue all the way to the threshold. The optimal choices for these firms satisfy the system of equations given by (2), (3) and (4), with enforcement intensity $\phi_{1}$ instead of $\phi_{0}$ and thus lower concealed income. Notice that in this baseline model with homogeneous resource costs and monitoring effort, any two firms with the same productivity respond identically to the LTU. The bunching response by firms with $\psi \in\left(\psi^{L}, \psi^{M}\right]$ therefore generates a "hole" in the post-LTU density, as depicted by the solid red line in Figure 1.

To obtain a measure of the behavioral response to the notch, we use a first-order approximation to relate the number of bunching firms to the change in the marginal buncher's reported revenue, following the bunching methodology first proposed by Saez (2010). For analytical simplicity, consider the case in which the LTU raises enforcement intensity by a small amount $d \phi=\phi_{1}-\phi_{0}>0$, such that bunching firms adjust their reported revenue by $d \bar{y}^{M}$. The adjustment is proportional to $d \psi=\psi^{M}-\psi^{L}$, the difference in productivities between the marginal buncher and the firm that locates at the notch before the LTU is introduced. Since there is a direct mapping between the productivity distribution $d_{0}(\psi)$ and the pre-LTU reported revenue distribution $g_{0}(\bar{y})$, we can define the number of bunching firms at the threshold as

$$
B=\int_{y^{L}}^{y^{L}+d \bar{y}^{M}} g_{0}(\bar{y}) d \bar{y} \approx g_{0}\left(\bar{y}^{L}\right) d \bar{y}^{M},
$$

where $g_{0}\left(\bar{y}^{L}\right)$ denotes the height of the pre-LTU density distribution at the threshold. ${ }^{14}$ The change in reported revenue by the marginal buncher $d \bar{y}^{M}$ can be interpreted as the length, in million euros, of the interval where the density is zero. In other words, the length of the hole in the distribution. The number of bunching firms that respond to the notch depends positively on the increase of monitoring effort and negatively on the extent of resource costs associated to tax evasion. Using the approximation in (8), we define the general bunching estimator $b$ as the ratio of excess bunching over the height of the counterfactual density at the LTU threshold,

$$
b \equiv \frac{B}{g_{0}\left(y^{L}\right)} \approx d \bar{y}^{M}
$$

\footnotetext{
${ }^{14}$ The approximation in (8) assumes that the pre-LTU density $g_{0}(\bar{y})$ is approximately flat in the neighborhood of the enforcement threshold $y^{L}$.
} 


\subsection{Heterogeneous Firms}

In the baseline model outlined above, we assume that (i) a discrete jump in monitoring intensity translates into the same change in enforcement intensity for all firms above the LTU threshold, and (ii) all taxpayers face the same resource costs of evasion. Given these simplifying assumptions, the model predicts bunching at the LTU threshold (with zero mass of firms in an interval just above it), and that all the variation in firms' reported revenue is due to differences in productivity. We now extend the model to introduce heterogeneity across firms in both enforcement intensity and resource costs. We show how this heterogeneity leads to different incentives to bunch for firms with the same productivity level. As a consequence, the extended model no longer predicts a hole in the post-LTU revenue distribution, and allows us to disentangle firms' structural response to effective tax enforcement from the average response attenuated by the presence of high resource costs.

\section{Heterogeneous Enforcement Intensity}

We assume now that the effectiveness of monitoring efforts to detect evasion depend on the traceability of misreported transactions. An increase in the tax authority's resources devoted to monitoring is more effective to uncover evasion by firms that sell mostly to other businesses, because these transactions generate a paper trail, compared to firms that sell mostly to final consumers, whose transactions are much harder to trace. This implies that, at each productivity level, firms' composition of revenue affects the effectiveness of the LTU. Hence, the LTU threshold leads to different changes in enforcement intensity across firms, creating stronger incentives to bunch for firms whose misreported transactions are easily detectable by the tax authority.

To model the heterogeneity of monitoring effort among firms at the same productivity level, assume a joint distribution of productivities and enforcement intensity with density $\widetilde{h}(\psi, \phi)$ on the domain $(\underline{\psi}, \bar{\psi}) \mathrm{x}\left(\phi_{0}, \bar{\phi}\right)$. For the group of firms with pre-reform reported revenue just above the threshold, $y^{L}$, the behavioral response for each enforcement intensity level is characterized by the set of conditions presented in the baseline LTU model. At each enforcement intensity $\phi$, determined by firms' composition of revenue, the notch provides incentives to bunch for firms in the pre-LTU density interval defined by $\left(y^{L}, y^{L}+d \bar{y}_{\phi}^{M}\right)$, where the reaction of the marginal buncher $d \bar{y}_{\phi}^{M}$ is increasing in $\phi$. The increase in enforcement intensity is higher for taxpayers with a larger proportion of easily traceable transactions that then find it more profitable to bunch at the threshold. In contrast, firms with a high proportion of costly-traceable revenue experience a lower increase in enforcement intensity, and thus have lower incentives to bunch. 
In the presence of heterogeneous responses due to differential enforcement intensity among firms with the same productivity, we can estimate the average reported revenue response from the observed bunching at the LTU threshold. Let $\widetilde{g}_{0}(\bar{y}, \phi)$ be the joint distribution of reported revenue and enforcement intensity distribution when enforcement intensity is constant at $\phi$, and denote by $g_{0}(\bar{y}) \equiv \int_{\phi} \widetilde{g}_{0}(\bar{y}, \phi) d \phi$ the unconditional reported revenue distribution absent the tax enforcement notch. Assuming that the counterfactual density is roughly flat around the LTU threshold, we can write the excess mass of bunching at the threshold as

$$
B=\int_{\phi} \int_{y^{L}}^{y^{L}+d \bar{y}_{\phi}^{M}} \widetilde{g}_{0}(\bar{y}, \phi) d \bar{y} d \phi \approx g_{0}\left(y^{L}\right) \cdot E\left[d \bar{y}_{\phi}^{M}\right],
$$

where $E\left[d \bar{y}_{\phi}^{M}\right]$ is the average response in reported revenue for the marginal buncher at each enforcement intensity level generated by the introduction of the LTU. We denote by $b_{a v}$ the estimator for the average bunching response, which is the ratio of excess bunching over the counterfactual reported revenue density at the threshold,

$$
b_{a v} \equiv \frac{B}{g_{0}\left(y^{L}\right)} \approx E\left[d \bar{y}_{\phi}^{M}\right]
$$

\section{Heterogeneous Resource Costs of Evasion}

Resource costs of evasion can differ across firms for multiple reasons. For instance, the costs of evasion might vary depending on firms' size and the complexity of their operations Kleven, Kreiner and Saez (2009), the preferences of the managers (e.g. risk aversion and honesty), or the number of business opportunities foregone because trading partners do not accept misreported transactions Chetty (2009). This implies that, at each productivity level, there is a distribution of resource costs that create heterogeneous incentives for revenue misreporting. These resource costs can be so large ("prohibitive") that some firms do not evade taxes at all, or they don't react to the introduction of the LTU.

We analyze the impact of prohibitive resource costs on the response to the LTU adapting the approach of Kleven and Waseem (2013), a paper that considers the presence of large optimization frictions to rationalize the lack of response to a taxation notch. Let $\alpha(\bar{y}, \phi)$ denote the proportion of firms with prohibitive resource costs to evade taxes at each level of reported revenue level and enforcement intensity. For analytical simplicity, we assume that this proportion is constant in the bunching segment, such that $\alpha(\bar{y}, \phi)=\alpha$ for $\bar{y} \in\left(y^{L}, y^{L}+d \bar{y}_{\phi}^{M}\right)$ and all $\phi$. Assuming that the pre-LTU reported revenue density is locally flat in the neighborhood of the threshold, the excess bunching mass at the 
threshold is now given by

$$
B_{r c}=\int_{\phi} \int_{y^{L}}^{y^{L}+d \bar{y}_{\phi}^{M}}[1-\alpha(\bar{y}, \phi)] \cdot \widetilde{g}_{0}(\bar{y}, \phi) d \bar{y} d \phi \approx g_{0}\left(y^{L}\right) \cdot(1-\alpha) \cdot E\left[d \bar{y}_{\phi}^{M}\right],
$$

where $E\left[d \bar{y}_{\phi}^{M}\right]$ is the average response to the threshold, and $(1-\alpha)$ determines the extent to which that response is attenuated by resource costs. Considering that any mass in the bunching segment results from high resource costs, we can estimate the (constant) proportion of firms with prohibitive costs to react, the "frictioners", as

$$
\alpha \equiv \frac{\int_{y^{L}}^{y^{L}+d \bar{y}_{\phi}^{M}} g(\bar{y}) d \bar{y}}{\int_{y^{L}}^{y^{L}+d \bar{y}_{\phi}^{M}} g_{0}(\bar{y}) d \bar{y}}
$$

where $g(\bar{y})$ is the observed post-LTU reported revenue density and $g_{0}(\bar{y})$ is the counterfactual pre-LTU density. We use the approximation in (12) and the estimation of $\alpha$ to derive a bunching parameter that measures the response to effective tax enforcement correcting for the attenuation due to resource costs, which we express as

$$
b_{r c} \equiv \frac{B}{g_{0}\left(y^{L}\right) \cdot(1-\alpha)} \approx E\left[d \bar{y}_{\phi}^{M}\right]
$$

Expression (14) indicates that the larger the number of bunching firms and the smaller the hole in the bunching range (i.e. higher presence of frictioners) the larger is the response to effective tax enforcement. This parameter provides a lower bound on the response to the LTU when the distribution of resource costs is positively related with firm size, and thus the proportion of frictioners is increasing in the bunching region. ${ }^{15}$ Instead, when the LTU creates heterogeneity of enforcement intensity across taxpayers in the bunching segment, the parameter measures the response by firms most affected by the increase in monitoring effort. Hence, with an homogeneous distribution of resource costs, the bunching estimator (14) provides an upper bound on the average response to effective tax enforcement in the population of firms.

\section{Empirical Strategy}

This section presents the empirical procedure to estimate the reported revenue response of firms to a tax enforcement notch [created by the introduction of a LTU]. To quantify this response, we adapt the techniques from the bunching literature in individual taxation (Saez, 2010; Chetty et al., 2011; Kleven and Waseem, 2013) to estimate the bunching

\footnotetext{
${ }^{15}$ The downward bias is small when firms in the bunching segment have similar/homogenous distribution of resource costs at each productivity level.
} 
parameters derived in the previous section. We then introduce an adjustment to quantify the reaction that would be observed in the absence of high resource costs that constrain firms' responses to the notch.

\subsection{Standard Bunching Estimator}

The basic procedure to estimate the reaction of firms to a LTU relies on constructing a counterfactual distribution of reported revenue in the absence of a tax enforcement notch, and comparing it with the observed distribution. To build the counterfactual, we fit a high-degree polynomial to the observed density, excluding an interval around the threshold. We discuss below how the excluded interval is determined. Dividing the data in small bins of width $w$, we estimate the polynomial regression

$$
F_{j}=\sum_{i=0}^{q} \beta_{i} \cdot\left(y_{j}\right)^{i}+\sum_{k=y_{l b}}^{y_{u b}} \gamma_{k} \cdot \mathbb{1}\left(y_{j}=k\right)+\eta_{j}
$$

where $F_{j}$ is the number of firms in bin $j, q$ is the order of the polynomial, $y_{j}$ is the revenue midpoint of bin $j, y_{l b}$ and $y_{u b}$ are the lower and upper bound of the excluded interval (respectively), and the $\gamma_{k}$ 's are intercept shifters for each of the bins in the excluded interval. Then, using the estimated coefficients from regression (15), we estimate the counterfactual distribution of reported revenue, that is,

$$
\widehat{F_{j}}=\sum_{i=0}^{q} \widehat{\beta}_{i} \cdot\left(y_{j}\right)^{i}
$$

The latter expression excludes the $\gamma_{k}$ shifters to ensure that the counterfactual density is smooth around the threshold. Comparing this counterfactual density to the observed distribution we can estimate the excess bunching mass to the left of the threshold $(B)$, and similarly the missing mass to the right of the threshold $(H)$, given by

$$
\widehat{B}=\sum_{j=y_{l b}}^{y^{L}}\left(F_{j}-\widehat{F_{j}}\right) \geq 0 \quad \text { and } \quad \widehat{H}=\sum_{j=y^{L}}^{y_{u b}}\left(\widehat{F_{j}}-F_{j}\right) \geq 0 .
$$

Determining the lower and upper bounds of the excluded region in a consistent way is critical for this estimation method to provide credible estimates. We follow the approach proposed by Kleven and Waseem (2013) to determine these bounds. This procedure imposes that the areas under both the counterfactual and the observed density have to be equal, and thus the missing area $(H)$ has to be equal to the excess mass $(B)$. Implicitly, this is equivalent to assuming that all responses to the tax enforcement notch are on the intensive margin (i.e., firms don't go out of business due to the introduction of the LTU, 
they only adjust their reported revenue). To obtain consistent bunching estimates, we first fix the lower bound $y_{l b}$ approximately at the point where the shape of the observed distribution changes due to the bunching response. ${ }^{16}$ Second, we set the upper bound at $y_{u b} \approx y^{L}$ and then run regression (15) multiple times, increasing the value of $y_{u b}$ by a small amount after each iteration. When bunching is substantial, the first few iterations yield large estimates of $\widehat{B}$ and small estimates of $\widehat{H}$. This estimation procedure iterates until reaching a value of $y_{u b}$ such that missing and bunching areas converge, i.e $\widehat{B}=\widehat{H} \cdot{ }^{17}$

Once we have estimates for the number of bunching firms $B$ and the counterfactual density at the threshold $g_{0}(\bar{y})$, we can estimate the bunching parameter $b$ defined in equation (9). The explicit formula for the estimator is given by

$$
\widehat{b}=\frac{\widehat{B}}{\left[\frac{1}{1+\left(y^{L}-y_{l b}\right) / w}\right] \sum_{j=y_{l b}}^{y^{L}} \widehat{\beta}_{i} \cdot\left(y_{j}\right)^{i}}
$$

where $\left[1+\left(y^{L}-y_{l b}\right) / w\right]$ is the number of excluded bins below the threshold.

Since we apply this estimation to the universe of firms affected by the presence of the notch, rather than a random sample, there is no sampling error and therefore we cannot construct the usual confidence intervals. To test whether the point estimates are statistically significant, we sample the residuals from regression (15) a large number of times (with replacement) to obtain bootstrapped standard errors. ${ }^{18}$

\subsection{Adjusted Bunching Estimator: Resource Costs}

In the theoretical section we derived the parameter $b_{r c}$, which identifies the response to the LTU that would be observed in the absence of prohibitive resource costs. In order to estimate this parameter, we need to quantify $\alpha$, that is, the proportion of firms locating in the excluded interval $\left(y^{L}, y_{u b}\right]$ determined by the (convergence) method compared to the estimated counterfactual density. We use this measure to reweigh the bunching estimator in order to obtain the adjusted bunching estimator $\widehat{b}_{r c}=\frac{\widehat{b}}{1-\alpha}$. In the presence of a notch, we can interpret estimates of $\widehat{b}_{r c}$ as an upper bound of the firms' response to effective tax enforcement. As before, we calculate standard errors using bootstrapping procedure described above. ${ }^{19}$

\footnotetext{
${ }^{16}$ Even though there is some discretion in the choice of the lower bound, we show in section 5 that the bunching estimates resulting from a range of values of $y_{l b}$ are fairly stable.

${ }^{17}$ In the empirical application there is a finite number of bins, so we impose the weaker condition that the ratio be "close" to one, i.e. $\hat{H} / \hat{B} \in[0.9,1.1]$.

${ }^{18}$ We thank Michael Best for sharing his Stata code to perform the bootstrapping routine. In all the results shown below, we perform 200 iterations to obtain the standard errors. Using a larger number does not affect our results.

${ }^{19}$ Kleven and Waseem (2013) propose a similar method to account for optimization frictions, although in their case there is a strictly dominated region in which no taxpayer should locate under any preferences,
} 


\section{Institutional Context and Data}

To test and quantify the predictions of the theoretical framework, we take advantage of the presence of a tax enforcement notch in Spain. We summarize below the main characteristics of the Spanish Large Taxpayers Unit (LTU), which applies stricter enforcement intensity on firms above an arbitrary revenue threshold. We also describe two other policy thresholds relevant for tax administration and the dataset used in our empirical analysis.

\subsection{Tax Administration Thresholds: the Spanish LTU}

The Spanish tax authority established a LTU (Unidades Regionales de Gestion de Grandes Empresas) in 1995 to increase its monitoring effort on the largest taxpayers. To define a "large firm" the tax authority established a threshold at $€ 6$ million in annual operating revenue that has not been modified since then. ${ }^{20}$ The number of firms in the LTU census (excluding public companies) increased from 16,713 in 1999 to 34,923 in 2007. Such a sharp increase was due mainly to strong economic growth and an annual inflation rate around $3 \% .{ }^{21}$ Despite the fact that the LTU includes only about $2 \%$ of all firms that submit a corporate income tax return, firms in the LTU report about $80 \%$ of all taxable profits and two-thirds of total sales subject to VAT, and they employ around $40 \%$ of private sector wage-earners (AEAT, 1999-2008).

Businesses just above and below the LTU threshold face the same corporate income tax rates and the same administrative requirements related to invoicing, accounting and information reporting. Therefore, holding everything else constant, all their transactions leave the same amount of paper trail. The key difference we exploit in our empirical strategy is the fact that enforcement intensity is higher for firms above the threshold. Indeed, the LTU has more human resources to monitor tax returns, allowing it to perform comprehensive tax audits on approximately $10 \%$ of large firms each year, while barely $1 \%$ of firms below the threshold are audited (AEAT, 1999-2008). Furthermore, the LTU makes heavier use of the available technological resources to detect inconsistencies in firms' reported transaction by cross-checking tax returns. ${ }^{22}$ Overall, the Spanish LTU

because the take-home pay falls as income rises due to the design of the Pakistani income tax. In our setting, there is no strictly dominated region because there may be heterogeneity in the resource costs of evasion faced by firms.

${ }^{20}$ The threshold was originally set at 1 billion pesetas, the official currency at the time. The fixed exchange rate is 166.386 pesetas per euro, so the threshold is exactly at $€ 6.010121$ million. In 2006 , an additional threshold of $€ 100$ million in operating revenue was established to determine eligibility to the Central Office for Large Firms, a select group of the largest firms within the LTU.

${ }^{21}$ The overall staff of the tax authority, and the LTU in particular, remained almost constant during this period, but the LTU was endowed with better technological resources to monitor the rising number of taxpayers (AEAT, 1999-2008).

${ }^{22} \mathrm{As}$ an example of its abundance of resources, the LTU has capacity to process electronic VAT declarations on a monthly basis rather than the quarterly frequency for the rest of firms. This reporting 
provides quasi-experimental variation in the monitoring effort on large firms with the same paper trail requirements, allowing us to examine firms' responses to effective tax enforcement.

Corporate Income Tax Threshold. The standard rate in the corporate income tax was $35 \%$ of taxable profits in the period 1999-2007. A lower rate of $30 \%$ was applied to firms under a revenue threshold that was modified over time: from $€ 1.5$ million in 1999 up to $€ 10$ million in 2010 (full details provided in Table A.2). The cutoff for this tax break overlapped with the LTU threshold in 2004, but was different in the rest of the years. The lower rate was applied only to the first $€ 90,121$ of taxable profits $(€ 120,202$ since 2005) creating a notch for eligible firms with low taxable profits, and a kink for those with high profits.

External Audit and Abbreviated Returns Threshold. Firms are required by law to have their annual accounts audited by an external private firm if they fulfill two of the following criteria for two consecutive years: (i) annual revenue above $€ 4.75$ million; (ii) total assets above $€ 2.4$ million; ${ }^{23}$ and (iii) more than 50 employees on average during the year. These criteria also determine whether a firm can use the abbreviated form of the corporate income tax return, rather than the standard (long) version. These requirements create compliance costs, ${ }^{24}$ and the private audit information could complement tax enforcement because auditors face legal responsibility if any misreporting is found.

\subsection{Data}

In the empirical analysis we use data from financial statements that, according to the law, all Spanish firms must submit to the Commercial Registry (Registro Mercantil Central). The micro-data compiled and digitalized by Amadeus, a European-level data set published by Bureau van Dijk, provides information for each firm such as business name, location (5-digit post code), sector of activity (4-digit NAICS ${ }^{25}$ code), 26 balance sheet items, 26 profit and loss account items, and 32 standard financial ratios. ${ }^{26}$ Table A.4 in

\footnotetext{
requirement might impose a minor compliance cost to LTU-eligible firms compared to ineligible ones.

${ }^{23}$ The revenue limit was originally 790 million pesetas (€4.748 million), and the assets limit was 395 million pesetas (€2.374 million).

${ }^{24}$ The yearly fee charged by private audit firms is in the range $€ 10,000$ - $€ 30,000$ for firms with revenue close to $€ 4.75$ million, a small but non-negligible expenditure ( 0.2 to $0.6 \%$ of total revenue, but 4 to $12 \%$ of reported profits on average).

${ }^{25}$ NAICS stands for North-American Industry Classification System.

${ }^{26}$ For the purposes of this paper, we accessed the online version of Amadeus in November 2011. Since the dataset is continuously updated, the information currently available in the online version may have suffered some changes, e.g., businesses that are inactive for four consecutive years are dropped from the dataset.
} 
the online appendix compares the number of firms in the Amadeus data to the number of corporate tax returns reflected in official statistics, by levels of operating revenue. Very small firms are underrepresented in the data because they tend to submit their financial statements on paper rather than electronically, in which case Amadeus is less likely to include them. However, there is complete data for more than $80 \%$ of firms with reported revenue between $€ 3$ and $€ 9$ million, the range that is most interesting for our empirical analysis. Given that there is information on almost the universe of firms in the relevant size range, this dataset is well suited to examine firms' responses to the Spanish LTU.

The dataset contains information on the annual net revenue from sales, the key variable used to determine whether firms are eligible to the LTU and also the other policy thresholds discussed above. Firms have no incentive to report different amounts in their tax returns, because it would be extremely easy for the tax authority to cross-check the information. Hence, the annual revenue figure in the financial statements must match exactly with tax returns. The dataset also includes data on the two largest categories of firms expenditures: materials, which accounts for the cost of all raw materials and services purchased by the firm in the production process; and labor, which accounts for the total wage bill of a firm, including social security contributions charged on employees. The average number of employees reported during the fiscal year (same as the calendar year) is also available for the vast majority of firms. ${ }^{27}$

One important advantage of this dataset is its longitudinal structure, which allows us to study the dynamic behavior of firms around the threshold over time. One potential advantage of using financial statements instead of tax returns is the possibility of observing multiple margins of response in a single dataset. ${ }^{28}$ We explore dynamic behavior in subsection 5.3 and the anatomy of the response to the LTU threshold in subsection 5.4.

\section{Results}

We first document and quantify the reaction of Spanish firms to the notch in effective tax enforcement created by the introduction of a LTU. Second, we examine the heterogeneity of this response across sectors of activity and other dimensions of firm size such as the number of employees. The analysis provides insights on the effectiveness of monitoring effort depending on firm characteristics, and how resource costs of evasion attenuate the observed response. Third, we study the dynamic behavior of firms near the threshold to assess the degree of persistence in bunching behavior. Finally, we consider changes in

\footnotetext{
${ }^{27}$ This variable is missing for about $20 \%$ of the firms that report their total sales and material inputs. However, we do not detect a different proportion of missing values around the thresholds of interest.

${ }^{28}$ This is often not possible with administrative tax returns, because confidentiality rules prevent researchers from linking firms across different data sources.
} 
reported input expenditures as an alternative margin of response for firms.

\subsection{Static Bunching Estimation}

Figure 2 shows the empirical distribution of reported revenue for Spanish firms in the period 1999-2007, using micro-data from Amadeus. We focus on firms in the range between $€ 3$ and $€ 9$ million, centering the graph around the LTU threshold. There is substantial bunching of firms just below the LTU threshold, indicating that a significant number of firms attempt to avoid stricter tax enforcement. ${ }^{29}$ Figure 3 shows the counterfactual and empirical distributions of revenue, overlaid. Implementing the bunching estimation procedure derived in section 3 , we obtain a point estimate $\widehat{b}_{a v}=0.101$, which is statistically different from zero at the $1 \%$ level (the bootstrapped standard error is 0.007). This point estimate implies that firms reduce their reported revenue by about $€ 101,000$ (approximately $1.7 \%$ of total reported revenue) on average in response to the tax enforcement notch. As predicted by our theoretical framework, there is no "hole" in the distribution to the right of the LTU threshold, just a small dip. We hypothesize that firms face heterogeneous resource costs of evasion, which attenuates the bunching response by preventing some firms from responding. Using the adjusted bunching estimator, we obtain $\widehat{b}_{r c}=0.593$ (s.e. 0.122), implying that the marginal bunching firm with low adjustment costs reduces its reported revenue by about $€ 593,000$ (almost $10 \%$ of total reported revenue).

Robustness checks. We address several potential issues that may be raised about the robustness of the static bunching estimates. First, pooling several annual crosssections together increases the effective sample size allowing us to obtain more precise estimates, but it could mask differences in the response across years. Table 1 shows that bunching estimates are all significant and of similar magnitude in every year. ${ }^{30}$ We analyze the dynamic patterns of firm behavior in subsection 5.3 below. Second, the observed response could be affected by other size-dependent policies, such as the corporate income tax benefit for small firms discussed in the previous section. We do not find any evidence of bunching in response to this tax break over time. ${ }^{31}$ The lack of reaction to a five-percentage-point reduction in the corporate income tax rate (besides additional tax credits and fiscal advantages), is remarkable in a context where firms

\footnotetext{
${ }^{29}$ There is another spike in the distribution just below the External Audit threshold. This spike is smaller in magnitude and more difficult to interpret because the criteria to determine eligibility involve two other variables apart from reported revenue (employees and assets), as discussed in section 4 . For these reasons, in the remainder of the paper we focus on the response to the LTU threshold.

${ }^{30}$ The annual histograms are shown in Figure A.2 in the online appendix.

${ }^{31}$ As explained in section 4 , this threshold changes over time. The distribution of reported revenue under each of the thresholds is shown in Figure A.1 in the online appendix.
} 
respond strongly to a discontinuity in tax enforcement intensity. This evidence indicates that the perceived impact of strict tax enforcement is large for a significant proportion of Spanish firms. Third, the arbitrary selection of the lower bound of the excluded interval $y_{l b}$ could bias the estimation. We perform a sensitivity analysis of our main estimates selecting different values for the lower bound of the excluded region around our preferred value of $€ 5.4$ million, such that $y_{l b}=\{5.2, \ldots, 5.6\}$. Table 2 reports the results for the pooled 1999-2007 data. The resulting upper bound $y_{u b}$ is quite stable between $€ 6.62$ and $€ 6.78$ million. Similarly, point estimates for $\widehat{b}_{a v}$ are all in the interval $(0.097,0.102)$ and those of $\widehat{b}_{r c}$ are in the interval $(0.537,0.621)$. Overall, we conclude that any sensible choice of the lower bound $y_{l b}$ yields similar estimates of the bunching response.

\subsection{Heterogeneous Responses: Deterrence and Resource Costs}

According to the theoretical framework, firms face different incentives to misreport their revenue depending on (i) the deterrence effect of tax enforcement, which is determined by the tax authority's ability to detect tax evasion (i.e. the traceability of the paper trail); and (ii) the costs of such evasion, both direct and indirect, incurred by firms. To provide insights on the impact of these factors on tax compliance, we analyze evidence on cross-sectional differences in the behavioral response of firms to the tax enforcement notch created by the LTU.

Deterrence Effect across Sectors of Activity. On the deterrence component, we expect a larger response to the LTU for firms in the middle of the value chain, which sell mostly to other firms, than those at the last stage of the chain, which sell mostly to final consumers. Intuitively, it is much easier to detect misreported intermediate input sales than it is to detect unreported sales to final consumers, because the latter have no incentive to keep a receipt. Since we lack transaction-level data for each firm, we define 10 sectors of activity as an indicator of firms' position in the value chain. ${ }^{32} \mathrm{We}$ obtain the percentage of sales made to final consumers in each sector from the inputoutput tables of the Spanish economy in the year 2000, published by the Institute of National Statistics (INE). Figure 4 plots this percentage (in the horizontal axis) against the bunching estimates by sector (measured by $\widehat{b}_{a v}$, vertical axis). The relationship is downward-sloping, suggesting that the incentive to remain under the LTU threshold is stronger in sectors where a low percentage of sales is made to final consumers. On the top-left corner, heavy manufacturing, construction and building contractors, all of them with less than $10 \%$ of sales going to final consumers, present high bunching estimates (between 0.09 and 0.15). On the bottom-right corner, retailers, restaurants and hotels,

\footnotetext{
${ }^{32}$ Details about how we define each of the sectors can be found in the online appendix.
} 
which obtain more than $80 \%$ of their revenue from sales to final consumers, have much lower bunching response (between 0.04 and 0.07 ) to the same nominal revenue threshold. All the bunching estimates are significantly different from zero except for restaurants and hotels. The counterfactual and empirical distributions of revenue in the relevant sectors are shown in Figure 5, and all the point estimates are reported in Table 3.

The negative correlation between a high share of hard-to-trace transactions and the size of the bunching response at the enforcement notch is consistent with the predictions of our model. Holding the information requirements constant, the same increase in monitoring resources yields different effective enforcement intensities across firms depending on the traceability of their paper trail. The empirical results imply that the deterrence effect associated to higher monitoring resources is most effective for firms whose misreported transactions are easier to detect. In contrast, the increase in monitoring resources is less binding for firms that sell mostly to final consumers. Overall, the evidence indicates that paper trail requirements and monitoring effort are complements, and thus it is the interaction between these two elements that yields higher tax compliance.

Resource Costs and Firm Size. As shown above, a significant subset of firms report revenue just above the LTU threshold. We associate this lack of response to the presence of prohibitive costs that prevent firms from misreporting their revenue. Measuring resource costs of evasion is extremely difficult, because some of these costs are indirect (e.g., foregoing business opportunities) and others are hard to separate from regular expenses (e.g., hiring tax advisers). Instead of quantifying these costs, we take advantage of our empirical application to test whether they are related with the size and complexity of firms' operations Kleven, Kreiner and Saez (2009).

Our empirical setting provides variation in tax enforcement intensity for firms with similar size in terms of reported revenue. As discussed above, the change in tax enforcement intensity is related with the position of firms in the value chain, creating high incentives to bunch for firms with easily traceable transactions. Bunching estimates by sector of activity, which control for differences in tax enforcement effectiveness, also show that the lack of response due to resource costs, $\alpha$, is significant for sectors with large responses to the LTU. These results indicate that firm size, measured by reported revenue, is related with the magnitude of resource costs preventing firms to evade even when the tax authority undertakes a low effort to monitor their tax returns.

As a complementary analysis, we proxy firms' complexity using other dimensions of firms size, such as the number of employees and the stock of fixed assets. For a given level of reported revenue, we expect firms with more employees and/or fixed assets to exhibit lower bunching at the LTU threshold because they face higher resource costs of 
evasion. The results in the bottom panel of Table 3 show that bunching is stronger for firms with fewer than 50 employees, and for firms with less than $€ 2,4$ million in assets. ${ }^{33}$ These results indicate that additional firm's complexity contributes to increase its resource costs preventing them to react to the LTU. We conclude that, as predicted by Kleven, Kreiner and Saez (2009), large and more complex firms bear considerable resource costs that result in high tax compliance with low monitoring effort for a significant proportion of firms.

\subsection{Dynamic Firm Behavior}

The bunching analysis imposes a static perspective by pooling observations from different years. This means that many firms appear in the data in multiple years, but the graphical analysis does not control for potential autocorrelation. A potential issue with this estimation strategy is that persistent bunching behavior by a small group of firms could bias our cross-sectional estimates upward. ${ }^{34}$ We present below some descriptive evidence of firms' growth patterns and analyze the extent of bunching persistence to address this concern.

First, we compare the behavior of growing firms, defined as those reporting higher revenue in the current year than the previous year, and shrinking firms. Figure 6 shows that growing firms bunch very significantly at the threshold, whereas shrinking firms barely respond. This seems to indicate that firms perceive crossing the LTU threshold as a fixed cost, for example because they need to change the way they operate under stricter tax monitoring. The strong reaction of growing firms is further documented in Figure 7, which shows median revenue growth compared to current revenue. ${ }^{35}$ Median growth rates are close to $5 \%$ for most firms in the $€ 3-€ 9$ range, except for a sharp decline for firms approaching the threshold from below (i.e., those with revenue between $€ 5$ - $€ 6$ million). Overall, these patterns suggest that as small firms approach the threshold from below, a subset of them slows down their growth to avoid crossing it.

In order to assess more directly the hypothesis that there is a small number of persistent bunchers, we perform an additional test suggested by Marx (2012). The idea is to estimate whether firms are more likely to stay in the bunching region than in any other part of the revenue distribution. In order to precisely define the bunching region, we divide reported revenues in equally-sized bins of $€ 601,012$ (ten times wider than the

\footnotetext{
${ }^{33}$ We choose these reference thresholds because they are two of the eligibility criteria in the External Audit threshold.

${ }^{34}$ It is important to keep in mind that the LTU notch was fixed in nominal terms throughout the period under study, while inflation averaged $3 \%$ per year and real annual growth was close to $4 \%$. Thus, the notch moved down about $27 \%$ in real terms between 1999 and 2007.

${ }^{35}$ We define median growth rate in each revenue bin as $\Sigma_{i}$ median $\left(\ln \left(y_{i, t+1}\right)-\ln \left(y_{i, t}\right)\right)$. We use median instead of average growth rates because the latter take many extreme values.
} 
bins in the histogram of reported revenue). We define the "bunching bin" as the range of reported revenue between $€ 5.41-€ 6.01$ million. ${ }^{36}$ We then compare the fraction of firms that remain in the bunching bin after $h$ years to the fraction that remain in other revenue bins, where $h=\{1,2, \ldots, 6\}$. Formally, we estimate the equation

$$
\operatorname{Prob}\left[\operatorname{bin}\left(\bar{y}_{i t}\right)=\operatorname{bin}\left(\bar{y}_{i, t+h}\right)\right]=\alpha+\beta \text { BunchBin }_{i t}+y_{i t}+y_{i t}^{2}+\varepsilon_{i t},
$$

where the dependent variable is the fraction of firms that report revenue $\left(y_{i t}\right)$ in the same bin in years $t$ and $t+h$, and the dummy variable BunchBin $n_{i t}$ takes value one if $y_{i t} \in(5.4,6.0]$. We add a quadratic polynomial in current reported revenue as a way to control for the counterfactual probability that firms remain in a given revenue bin. ${ }^{37}$ In the actual regression, we use the distance to the threshold instead of the actual level of reported revenue. This allows us to interpret the constant term $\alpha$ as the fraction of firms near the notch expected to remain at their current revenue level $h$ years from now.

Figure 8 presents the results graphically. The top-left graph shows the probability that firms remain in the same revenue bin after one year. This probability decreases smoothly from about $30 \%$ in the range $y_{i t} \in(3.0,3.6)$ to $12 \%$ in the range $y_{i t} \in(9.4,10.0)$. However, there is a clear deviation from the trend at the bunching bin, where the proportion of firms that stay is $26.5 \%$, compared to the $20.7 \%$ predicted by the counterfactual. This means that a firm in the bunching bin is 28 percent ( 5.8 percentage points) more likely to remain in the same revenue bin one year later. The regression results for all values of $h$ are summarized in Table 4 . The coefficient on the BunchBin dummy is significant at the $5 \%$ level for all lags up to six years, but it is only economically significant for the short lags (up to two or three years). This short-term persistence suggests that bunching is generated by a group of growing of firms that changes over time. We conclude that the static bunching estimates are unlikely to be biased due to this short-term bunching persistence.

\subsection{Anatomy of the Response: Input Misreporting below the LTU Threshold}

We analyze the relative use of inputs reported by firms to learn about the mechanism behind firms' responses to stricter tax enforcement. To obtain testable hypothesis, we derive theoretical predictions on the average reported ratios of tax-deductible input expenditures over revenue around the LTU threshold (see section B in the online appendix

\footnotetext{
${ }^{36}$ The results are qualitatively similar for smaller bin widths, such as $€ 180,000$ or $€ 60,101$. Results available upon request.

${ }^{37}$ In the data, the probability of staying in a given revenue bin decreases with revenue for all values of $h$, because the equal-sized bins are proportionally smaller as we move to higher revenue levels.
} 
for a full derivation of the model). We obtain different predictions depending on whether firms' reaction is due to real (i.e. lower output) or evasion (increase of concealed revenue) adjustments. We enrich the range of predictions with the insights from an extended model that considers the possibility that firms have also incentives to misreport their inputs expenditures to evade their tax liabilities in the presence of multiple taxes (i.e. value-added tax, payroll taxes and corporate income tax). The set of predictions can be tested with simple graphical evidence from our dataset showing the average reported ratios of labor and material expenditures over revenue around the LTU threshold. We use these tests to rule out mechanisms of the reaction consistent with the theory, rather to identify causal effects of tax enforcement on firms' expenditures reporting.

Empirical Evidence and Theoretical Predictions. The top-left panel of Figure 9 plots the average reported ratio of material input expenditures over revenue on the vertical axis and reported revenue in the horizontal axis, both measured in year $t$, for the period 1999-2007. Each bin is $€ 120,202$ wide, which is twice as wide as the bins in the reported revenue histograms described above. ${ }^{38}$ The ratio slopes up in the reported revenue range between $€ 3$ and $€ 9$ millions with a concave shape, indicating that firms with larger revenue use an increasingly higher proportion of material inputs. The relative use of material inputs increases smoothly in reported revenue until reaching the LTU threshold where jumps sharply downwards by about two percentage points (from $66 \%$ to $64 \%$ ). The top-right panel of Figure 9 shows the same evidence for the reported ratio of labor expenditures over revenue. The pattern in this case is approximately the reverse: the ratio slopes down smoothly in reported revenue with an upward jump of one percentage point (from $15 \%$ to $16 \%$ ) at the LTU threshold.

According to our theoretical predictions (see section B in the online appendix), these patterns are not compatible with a real response to the LTU threshold. In that case, the reduction of production by the bunchers should have implied lower use of both inputs, resulting in a upward jump of both expenditure ratios at the threshold. The empirical patterns instead can be rationalized with an evasion response by buncher firms which also misreport their expenditures. As we show in section B in the online appendix, both CIT and VAT create incentives for evader firms to inflate material expenditures in order to claim larger tax credits. Moreover, those firms have incentives to hide labor expenditures to reduce their payroll tax liability and avoid the regulatory costs of hiring workers. Hence, when firms that misreport expenditures conceal revenue to bunch below the threshold, the model predicts a downward (upward) jump in the ratio of materials

\footnotetext{
${ }^{38}$ Wider bins reduce the amount of noise in the figures presented below. We do not adjust for inflation because the outcome variable is a ratio of two nominal amounts. We implicitly assume that the inflation on the output good is the same as for inputs.
} 
(labor) expenditures over revenue just at the LTU threshold.

A potential issue that may be raised is that labor-intensive firms could be less likely to bunch because prohibitive resource costs are strongly related with the number of employees. This would mechanically yield lower average labor expenditures in the interval just below the threshold creating discontinuities in the expenditures ratio due to a composition effect in the data. The bottom panels of Figure 9 provide a more disaggregated picture of labor expenditures that rejects this hypothesis. On the left, we do not observe a discontinuity of the average number of employees at the threshold. Instead, the right panel plots average gross wages (total wage bill divided by the number of employees), which features an upward jump at the threshold. This means that most of the shift in labor expenditures at the enforcement threshold is due to different reported wages and not a different number of employees. This evidence seems more consistent with the inputs evasion channel than with the composition-effect hypothesis. Even though this is not a definitive test, we take it as suggestive evidence that firms that manipulate their reported revenue to avoid the stricter tax enforcement by the LTU also misreport their input expenditures in order to evade multiple taxes.

\section{Concluding Remarks}

In this paper, we have investigated the effectiveness of exploiting information trails generated by business activities to enforce taxes. We first derive theoretical predictions on firms' responses to increases in the tax authority resources to verify the transactions reported by firms. We then test the predictions on firms' tax compliance using quasiexperimental variation in monitoring effort provided by the Large Taxpayers Unit (LTU) in Spain.

The empirical results show that firms react to avoid being under more effective tax enforcement reducing their reported revenue. This reaction is heterogeneous among firms depending on the traceability of their transactions, indicating the complementarity between monitoring effort and information requirements to reach tax compliance. In particular, we find larger reaction in sectors that sell intermediate goods where the information trail is easier to verify with more monitoring resources. Finally, we document that firms are able to misreport both labor expenditures and material acquisitions to evade taxes when the capacity to verify those transactions is low.

The results of the paper highlight the relevance of monitoring the information trail created by firms to ensure tax compliance. Firms are not only the third-party agent that helps to prevent individuals' tax evasion, but tax authorities must devote resources to verify their activities to reach effective tax enforcement. 


\section{References}

AEAT. 1999-2008. "Memoria de Administración Tributaria." Spanish Tax Authority (Agencia Estatal de Administración Tributaria).

Allingham, Michael, and Agnar Sandmo. 1972. "Income tax evasion: A theoretical analysis." Journal of Public Economics, 1: 323-338.

Amadeus. 1999-2007. "Database of comparable financial information for European companies, published by Bureau van Dijk."

Bastani, Spencer, and Hakan Selin. 2014. "Bunching and Non-Bunching at Kink Points of the Swedish Tax Schedule." Journal of Public Economics, 109: 36-49.

Best, Michael C. 2013. "Salary Misreporting and the Role of Firms in Workers' Response to Taxes: Evidence from Pakistan." London School of Economics.

Best, Michael C., and Henrik J. Kleven. 2013. "Housing Market Responses to Transaction Taxes: Evidence from Notches and Stimulus in the UK." London School of Economics.

Carrillo, Paul, Monica Singhal, and Dina Pomeranz. 2014. "Tax Me if You Can: Evidence on Firm Misreporting and Evasion Substitution." Harvard Kennedy School.

Chetty, Raj. 2009. "Sufficient Statistics for Welfare Analysis: A Bridge Between Structural and Reduced-Form Analysis." Annual Review of Economics, 1: 451-488.

Chetty, Raj, John Friedman, and Emmanuel Saez. 2013. "Using Differences in Knowledge Across Neighborhoods to Uncover the Impacts of the EITC on Earnings." American Economic Review, 103(7): 2683-2721.

Chetty, Raj, John Friedman, Tore Olsen, and Luigi Pistaferri. 2011. "Adjustment Costs, Firm Responses, and Micro vs. Macro Labor Supply Elasticities: Evidence from Danish Tax Records." Quarterly Journal of Economics, 126: 749-804.

Christensen, Kevin, Robert Cline, and Tom Neubig. 2001. "Total Corporate Taxation: "Hidden", Above-the-Line, Non-Income Taxes." National Tax Journal, $\operatorname{LIV}(3)$ : 495-506.

Devereux, Michael, Li Liu, and Simon Loretz. 2014. "The Elasticity of Corporate Taxable Income: New Evidence from UK Tax Records." American Economic Journal: Economic Policy, 6(2): forthcoming. 
Garicano, Luis, Claire LeLarge, and John van Reenen. 2013. "Firm Size Distrotions and the Productivity Distribution: Evidence from France." NBER Working Paper 18841.

Gordon, Roger, and Wei Li. 2009. "Tax Structures in Developing Countries, Many Puzzles and a Possible Explanation." Journal of Public Economics, 93: 855-866.

Guner, Nezih, Gustavo Ventura, and Yi Xu. 2008. "Macroeconomic Implications of Size-Dependent Policies." Review of Economic Dynamics, 11: 721-744.

IEF. 2011. "Evolución del Sistema Fiscal Español: 1978-2010." Instituto de Estudios Fiscales.

IMF. 2002. "Improving Large Taxpayers' Compliance: A Review of Country Experience." International Monetary Fund, Washington DC. Team led by Katherine Baer.

Kleven, Henrik, and Mazhar Waseem. 2013. "Using Notches to Uncover Optimization Frictions and Structural Elasticities: Theory and Evidence from Pakistan." forthcoming at the Quarterly Journal of Economics.

Kleven, Henrik, Klaus Kreiner, and Emmanuel Saez. 2009. "Why Can Modern Governments Tax So Much? An Agency Model of Firms as Fiscal Intermediaries." NBER Working Paper 15218.

Kleven, Henrik, Martin Knudsen, Claus Kreiner, Soren Pedersen, and Emmanuel Saez. 2011. "Unable of Unwilling to Cheat? Evidence from a Tax Audit Experiment in Denmark." Econometrica, 79(3): 651-692.

Kopczuk, Wojciech, and David J. Munroe. forthcoming. "Mansion Tax: The Effect of Transfer Taxes on the Residential Real Estate Market." American Economic Journal: Economic Policy.

Kopczuk, Wojciech, and Joel Slemrod. 2006. "Putting Firms into Optimal Tax Theory." American Economic Review, Papers and Proceedings, 96(2): 130-134.

Kumler, Todd, Eric Verhoogen, and Judith Frias. 2012. "Enlisting Workers in Monitoring Firms: Payroll Tax Compliance in Mexico."

Marx, Benjamin. 2012. "Regulatory Hurdles and Growth of Charitable Contributions: Evidence from a Dynamic Bunching Design." Columbia University.

OECD. 2011. "Tax Administration in OECD and Selected non-OECD Countries: Comparative Information Series (2010)." Organisation for Economic Co-operation and Development. 
Onji, Kazuki. 2009. "The response of firms to eligibility thresholds: Evidence from the Japanese value-added tax." Journal of Public Economics, 93: 766-775.

Paula, Áureo De, and José Scheinkman. 2010. "Value-Added Taxes, Chain Effects, and Informality." American Economic Journal: Macroeconomics, 2: 195-221.

Pomeranz, Dina. 2013. "No Taxation Without Information: Deterrence and SelfEnforcement in the Value-Added Tax." Harvard Business School Working Paper 13-057.

Restuccia, Diego, and Richard Rogerson. 2008. "Policy Distortions and Aggregate Productivity with Heterogeneous Establishments." Review of Economic Dynamics, 11: $707-720$.

Saez, Emmanuel. 2010. "Do Taxpayers Bunch at Kink Points?" American Economic Journal: Economic Policy, 2(3): 180-212.

Slemrod, Joel. 2010. "Buenas Notches: Lines and Notches in Tax System Design." University of Michigan.

Slemrod, Joel, and Christian Gillitzer. 2014. Tax Systems. Cambridge, MA:MIT Press.

Slemrod, Joel, Marsha Blumenthal, and Charles Christian. 2001. "Taxpayer Response to an Increased Probability of Audit: Evidence from a Controlled Experiment in Minnesota." Journal of Public Economics, 79: 455-483.

Yaniv, Gideon. 1988. "Withholding and Non-Withheld Tax Evasion." Journal of Public Economics, 35: 183-204.

Yitzhaki, Shlomo. 1974. "A Note on "Income Tax Evasion: A Theoretical Analysis"." Journal of Public Economics, 3(2): 201-202. 


\section{Figures}

Figure 1: Theoretical Revenue Distribution

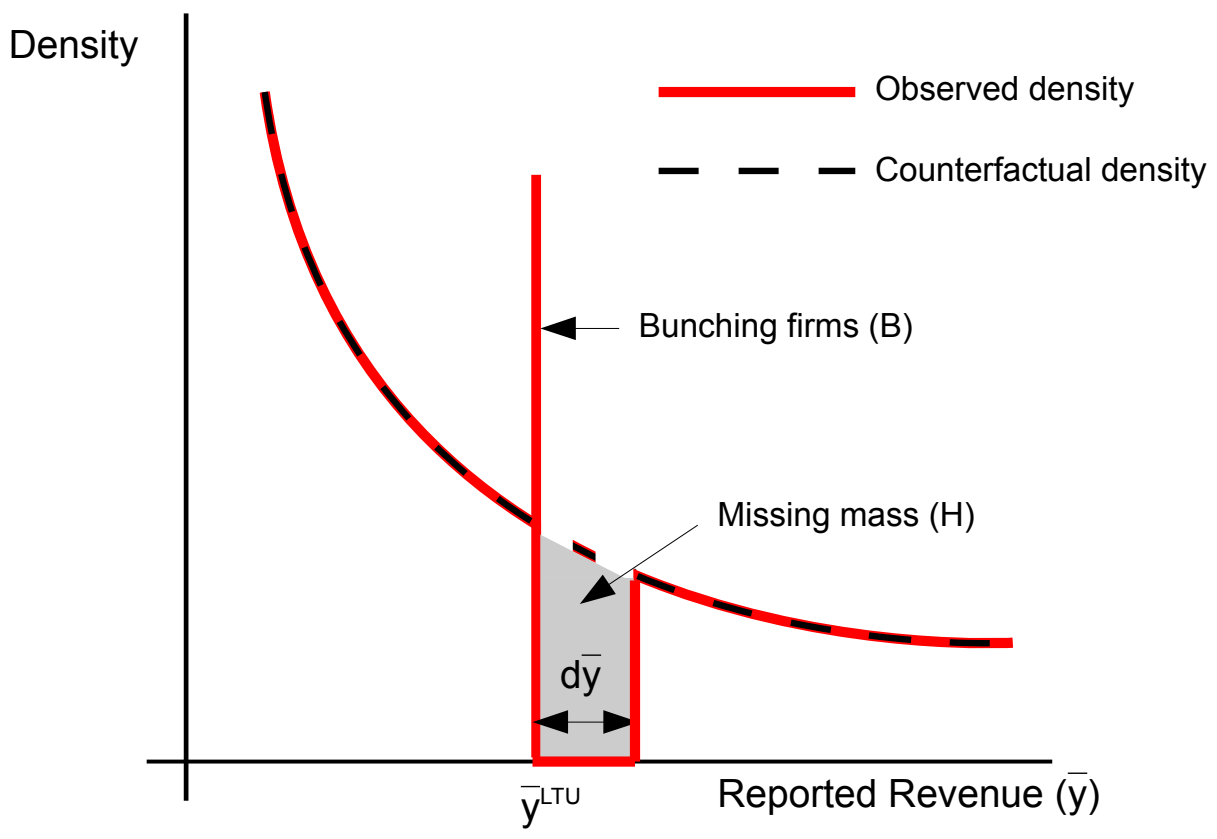

Note: this figure depicts the theoretical revenue distribution before and after the introduction of the Large Taxpayers Unit (LTU). Without the LTU, all firms face the same monitoring effort and the distribution of revenue is smoothly decreasing as depicted by the dashed (black) line. When the LTU is introduced, firms reporting revenue above $y^{L T U}$ face a higher enforcement intensity. A group of firms in an interval above $y^{L T U}$ respond to the new policy by underreporting more of their revenue to report exactly $\bar{y}=y^{L T U}$. This generates a spike at the threshold (with excess mass $B$ ), and an area of missing mass $(H)$ to the right of the threshold, as depicted by the solid (red) line. This plot assumes that there are homogeneous resource costs of evasion, so firms with the same productivity draw respond identically to fiscal incentives. Thus, no firm locates in the interval of length $d \bar{y}$ to the right of the LTU threshold. 
Figure 2: Operating Revenue Distribution

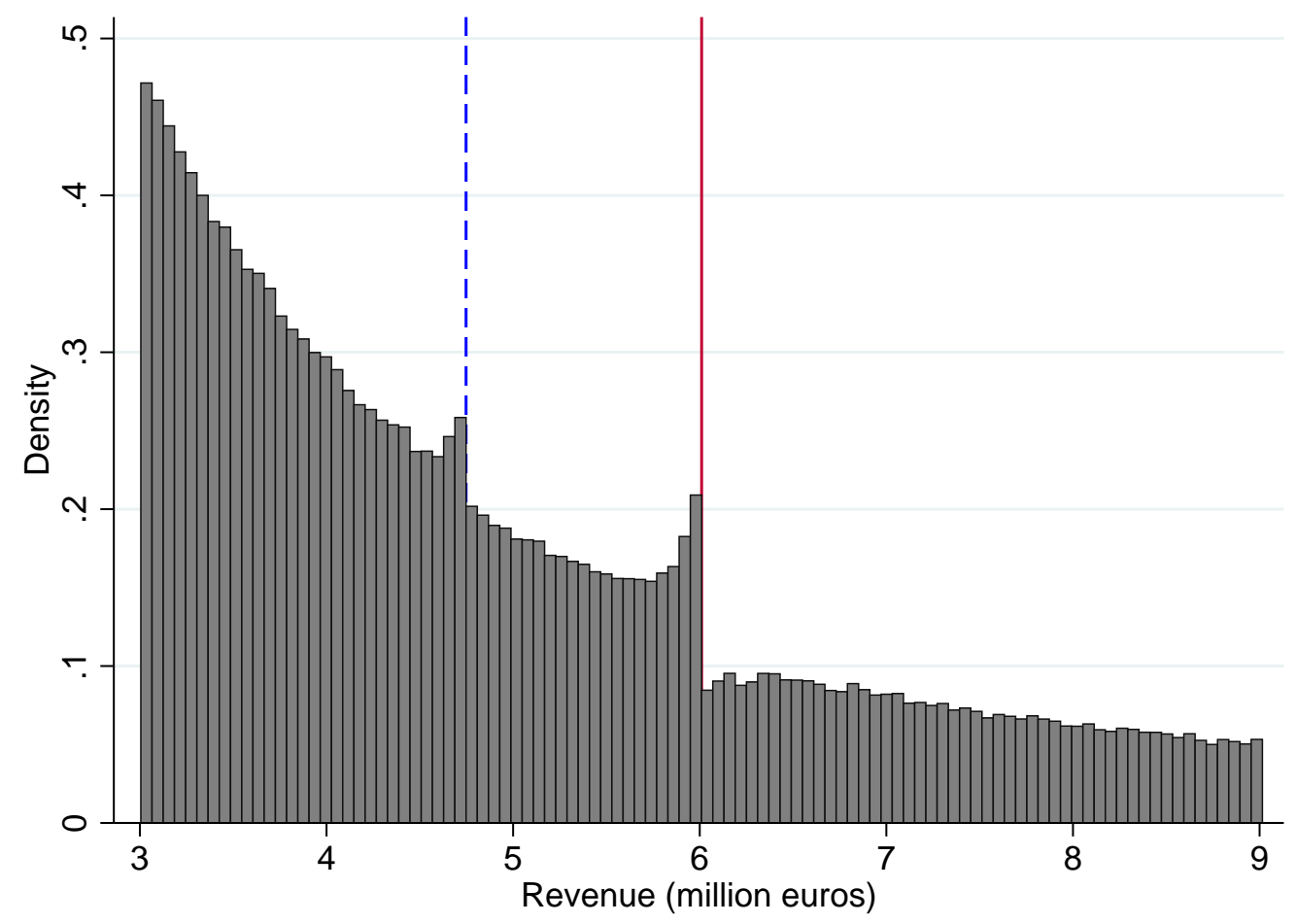

Note: this graph shows the distribution of operating revenue reported by Spanish firms, pooling annual observations from the period 1999-2007. The solid (red) line indicates the Large Taxpayers Unit (LTU) threshold (€6 million); the dashed (blue) line indicates the revenue threshold (€4.75 million) for the External Audit requirement. The bins are $€ 60,101$ wide, delimited such that no bin contains data both to the left and to the right of the relevant policy thresholds.

Source: annual data from the Amadeus dataset (published by Bureau van Dijk) for Spanish firms in the period 1999-2007. 
Figure 3: Counterfactual Distribution \& Bunching Estimates

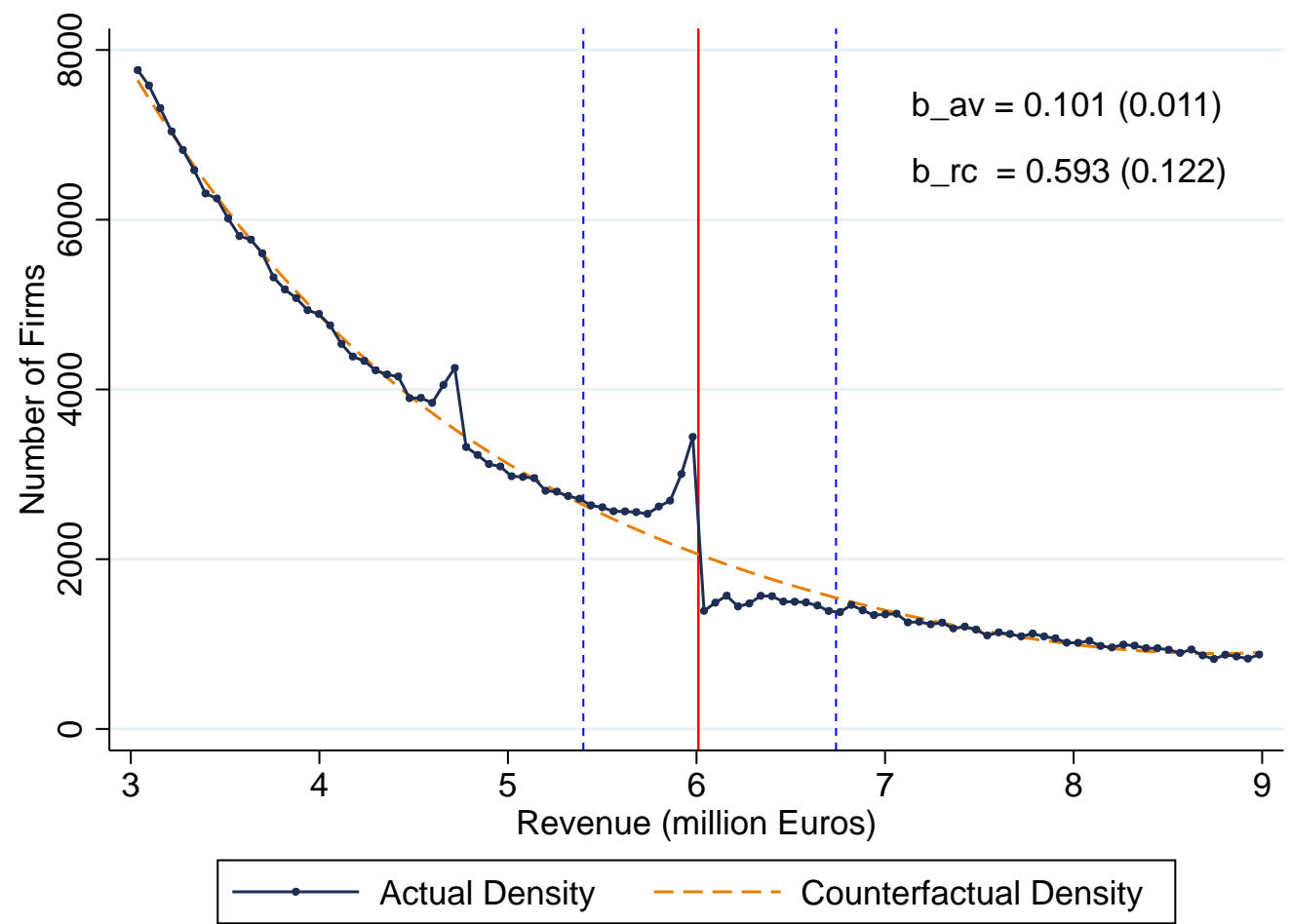

Note: this graph shows the reported distribution of revenue (dots connected by solid blue line) and the estimated counterfactual (orange dashed curve) for the period 1999-2007. The data for the true distribution are exactly the same as those used to construct the histogram in Figure 2. The vertical dotted blue lines indicated the bounds of the excluded region $\left(y_{l b}\right.$ and $\left.y_{u b}\right)$ chosen for the estimation of the counterfactual. To determine the value of $y_{u b}$, we fit a 4th-degree polynomial to the true density in multiple iterations, starting with $y_{u b} \approx y^{L T U}$ and increasing the value in small steps until we reach a point where the bunching mass $(B)$ equals the missing mass $(H)$, so that the integration constraint is satisfied. The average bunching parameter $\left(b_{a v}\right)$ estimates the adjustment in reported revenue for the average firm above the threshold, while $\left(b_{r c}\right)$ estimates the adjustment for the marginal bunching firm, accounting for the existence of resource costs of evasion that prevent some firms from responding to the notch. ( $\mathrm{N}=273,846$. Bin width $=€ 60,101$ ). 
Figure 4: Bunching Response by Sector of Activity

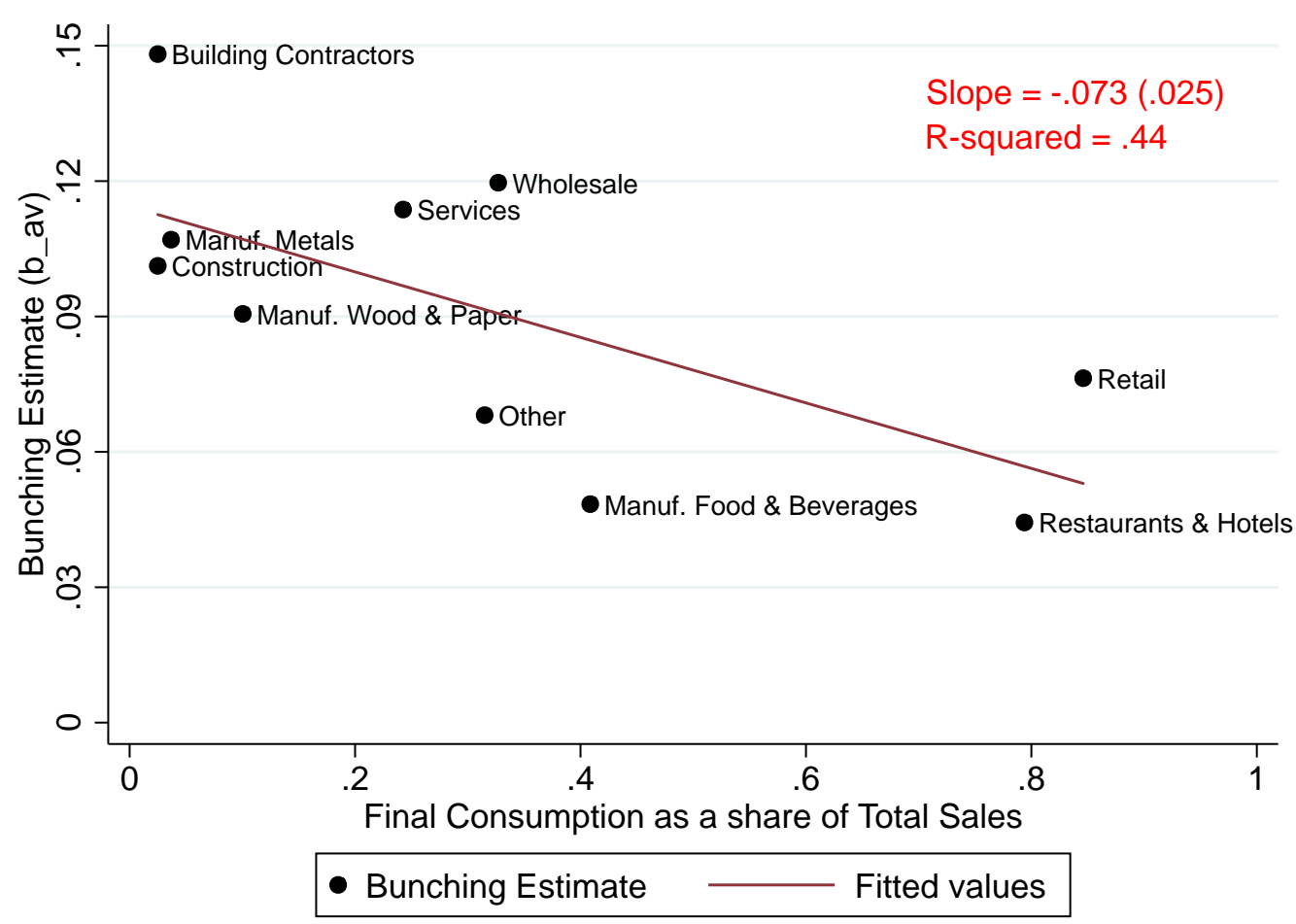

Note: the bunching measure $\widehat{b}_{a v}$ is calculated for each sector as explained in section 3 in the main text. Final consumption as a share of total sales in each sector is calculated using the year 2000 input-output tables for the Spanish economy, published by the National Statistics Institute (INE). (Details about this data source are provided in the online appendix.) The figure shows a negative relationship between bunching intensity by sector and the percentage of sales made to final consumers in each sector. This suggests that firms with mostly traceable revenue are more concerned about crossing the LTU threshold, because their ability to evade taxes by misreporting revenue is substantially reduced in the LTU. The slope coefficient reported is obtained by estimating a simple linear regression of the bunching estimates on final consumption share in each sector, using robust standard errors. 


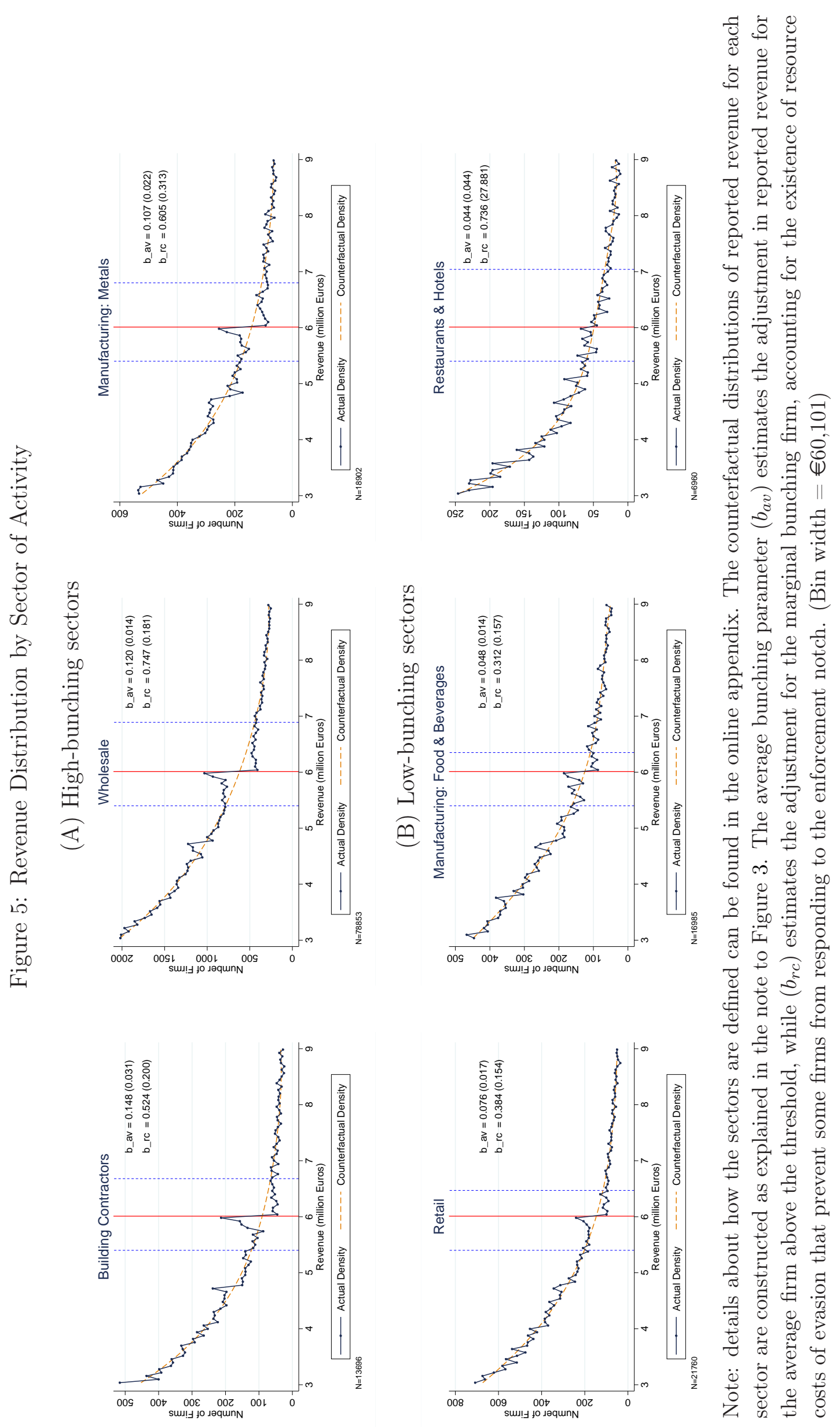


Figure 6: Growing vs. Shrinking Firms
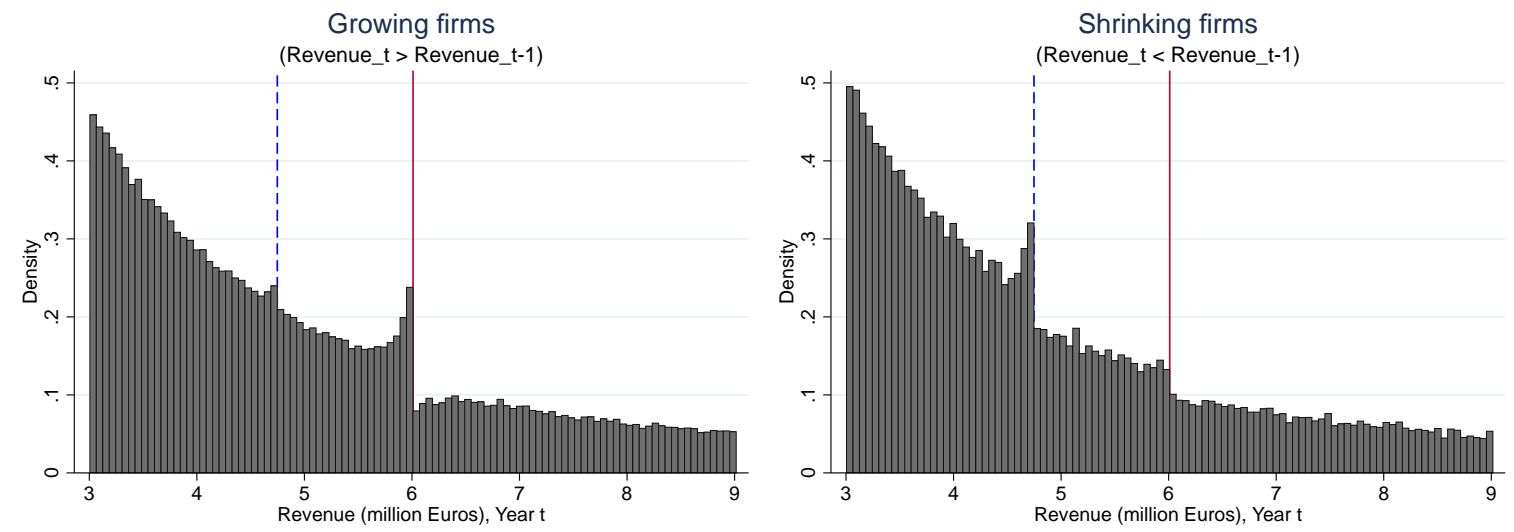

Note: these graphs show operating revenue distributions, pooling data for the period 1999-2007, for two subsamples of firms: those that are growing and those that are shrinking. A firm is defined as growing if its reported revenue in year $t$ is higher than in year $t-1$, i.e. $\bar{y}_{t}>\bar{y}_{t-1}$. Conversely, a firm is defined as shrinking if $\bar{y}_{t}<\bar{y}_{t-1}$. The dashed (blue) line indicates the revenue threshold (€4.75 million) for the External Audit requirement. The solid (red) line indicates the $€ 6$ million LTU threshold. (Bin width $=€ 60,101$ ).

Figure 7: Patterns of Revenue Growth


Note: the horizontal axis shows revenue in year $t$ in both diagrams. The diagram on the left shows the proportion of firms for which revenue increases between year $t$ and $t+1$. The diagram on the right shows median growth in reported revenue, defined as the median of $\left[\ln \left(y_{t+1}\right)-\ln \left(y_{t}\right)\right]$, experienced by firms in year $t+1$. The vertical red line indicates the LTU threshold. (Bin width $=€ 60,101)$ 
Figure 8: Bunching Persistence
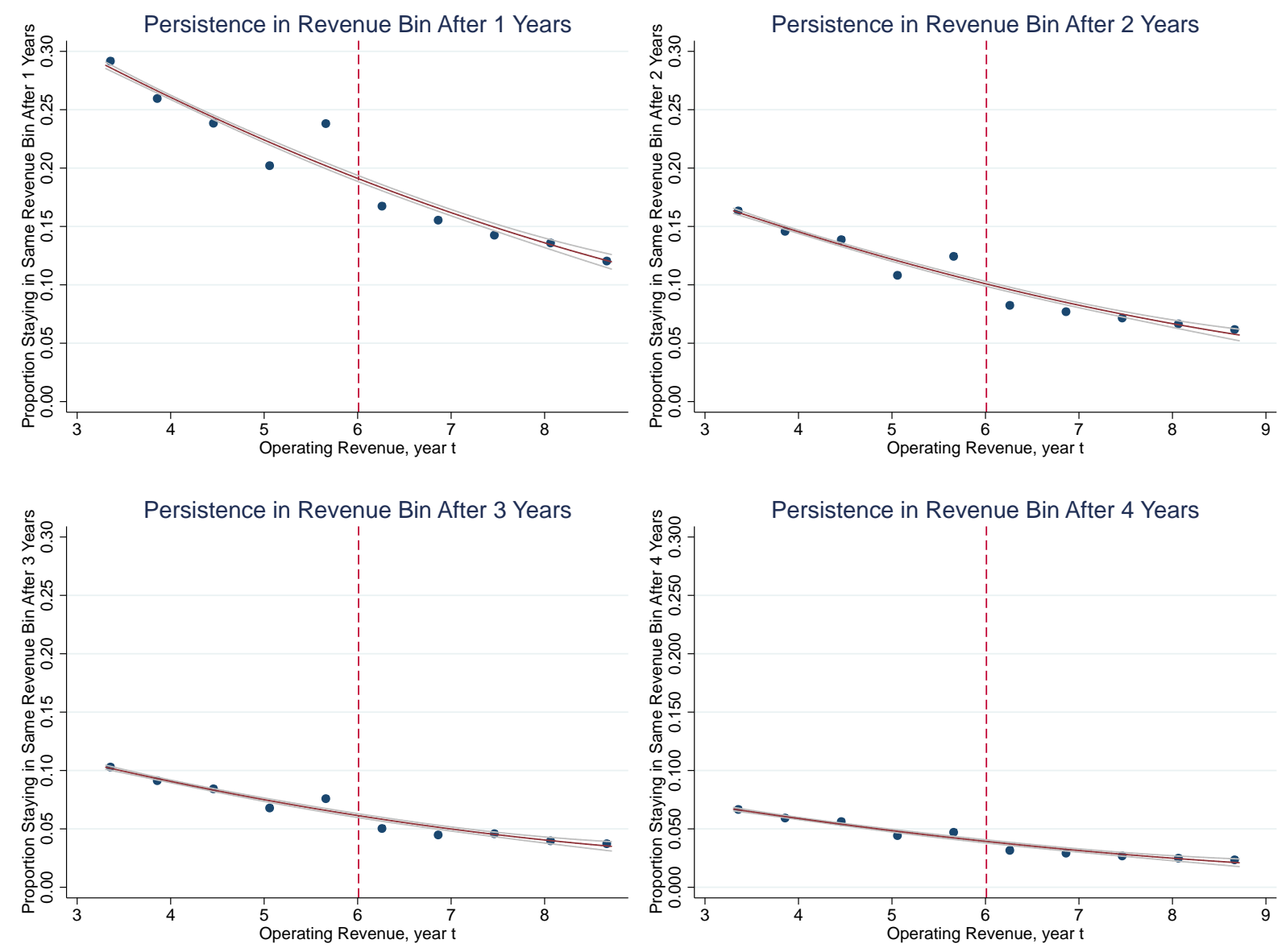

Note: these graphs show a measure of persistence in the bunching response. The dashed (red) vertical line indicates the LTU threshold. The blue dots indicate the proportion of firms that report revenues within the same bin both in year $t$ and year $t+h$, where $h$ is the number of years. The solid red curve is a quadratic fit of the bin averages, excluding the "bunching bin". We define the bunching bin as the interval of reported revenue $\bar{y} \in(5.41,6.01]$, consistent with the static bunching analysis. Narrower definitions of the bunching bin yield qualitatively very similar results. (Bin width $=€ 601,012$ ). 
Figure 9: Input Expenditures
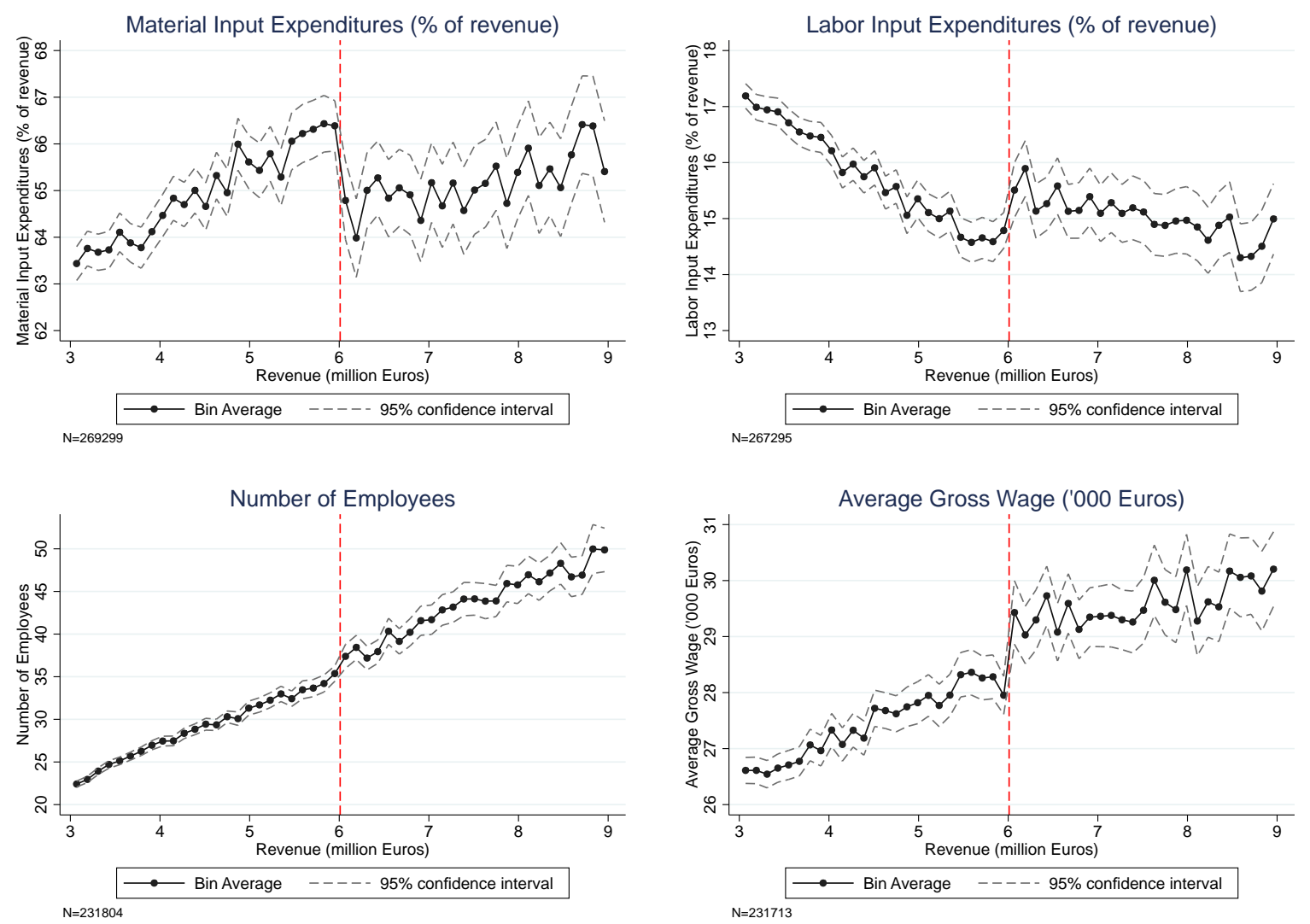

Note: these graphs show the average ratio of input expenditures over revenue (vertical axis) against reported revenue (horizontal axis), for the period 1999-2007. The dashed (red) vertical lines indicate the LTU threshold. The dotted lines denote bin averages and the grey dashed lines show $95 \%$ confidence intervals for each bin average. We trim outliers in the data by dropping the observations in the top and bottom $1 \%$ of the outcome variable. "Material input expenditures" includes all the intermediate inputs used by the firm for production. "Labor input expenditures" is the total wage bill of the firm, including social security contributions. "Number of employees" is calculated taking the average of the number of employees on the last day of each month. "Average gross wage" is defined as total labor expenditures divided by the number of employees. (Bin width $=€ 120,202$ ). 


\section{Tables}

Table 1: Bunching Estimations, by year

\begin{tabular}{|c|c|c|c|c|c|c|c|}
\hline \multirow{3}{*}{$\begin{array}{r}\text { Pooled data } \\
1999-2007\end{array}$} & \multicolumn{2}{|c|}{ Bunching Estimators } & \multicolumn{2}{|c|}{ \# of Firms } & \multicolumn{2}{|c|}{ Excl. Interval } & \multirow{2}{*}{$\begin{array}{c}\text { Obs. } \\
N \\
\end{array}$} \\
\hline & $b_{a v}$ & $b_{r c}$ & $B$ & $H$ & $y_{l b}$ & $y_{u b}$ & \\
\hline & $\begin{array}{c}0.101 \\
(0.011)^{* * *}\end{array}$ & $\begin{array}{c}0.593 \\
(0.120)^{* * *}\end{array}$ & 3910 & 3652 & 5.40 & 6.74 & 273,846 \\
\hline Annual data & & & & & & & \\
\hline 1999 & $\begin{array}{c}0.163 \\
(0.027)^{* * *}\end{array}$ & $\begin{array}{c}0.874 \\
(0.387)^{* *}\end{array}$ & 435 & 398 & 5.40 & 7.07 & 19,481 \\
\hline 2000 & $\begin{array}{c}0.123 \\
(0.023)^{* * *}\end{array}$ & $\begin{array}{c}0.751 \\
(0.410)^{*}\end{array}$ & 388 & 388 & 5.40 & 7.04 & 22,406 \\
\hline 2001 & $\begin{array}{c}0.097 \\
(0.021)^{* * *}\end{array}$ & $\begin{array}{c}0.693 \\
(0.553)\end{array}$ & 337 & 304 & 5.40 & 6.83 & 25,039 \\
\hline 2002 & $\begin{array}{c}0.077 \\
(0.017)^{* * *}\end{array}$ & $\begin{array}{c}0.584 \\
(0.272)^{*}\end{array}$ & 298 & 278 & 5.40 & 6.74 & 27,466 \\
\hline 2003 & $\begin{array}{c}0.097 \\
(0.016)^{* * *}\end{array}$ & $\begin{array}{c}0.590 \\
(0.229)^{* * *}\end{array}$ & 405 & 376 & 5.40 & 6.71 & 29,719 \\
\hline 2004 & $\begin{array}{c}0.122 \\
(0.018)^{* * *}\end{array}$ & $\begin{array}{c}0.775 \\
(0.270)^{* * *}\end{array}$ & 548 & 519 & 5.40 & 7.01 & 32,411 \\
\hline 2005 & $\begin{array}{c}0.091 \\
(0.015)^{* * *}\end{array}$ & $\begin{array}{c}0.462 \\
(0.134)^{* * *}\end{array}$ & 467 & 435 & 5.40 & 6.56 & 35,807 \\
\hline 2006 & $\begin{array}{c}0.096 \\
(0.014)^{* * *}\end{array}$ & $\begin{array}{c}0.480 \\
(0.123)^{* * *}\end{array}$ & 569 & 516 & 5.40 & 6.53 & 40,872 \\
\hline 2007 & $\begin{array}{c}0.086 \\
(0.015)^{* * *}\end{array}$ & $\begin{array}{c}0.479 \\
(0.154)^{* * *}\end{array}$ & 497 & 449 & 5.40 & 6.56 & 40,645 \\
\hline
\end{tabular}

Note: $b_{a v}$ is the average bunching response and $b_{r c}$ is the marginal buncher's response taking into account resource costs of evasion (both measured in million euros). Bootstrapped standard errors are shown below each estimate in parenthesis. $B$ is the number of firms above the counterfactual density of revenue in the range $y \in\left(y_{l b}, y^{L T U}\right)$, where $y$ is revenue, $y_{l b}$ is the lower bound of the excluded region (used to construct the counterfactual) and $y^{L T U}$ is the LTU threshold of $€ 6$ million. $H$ is the missing number of firms below the counterfactual density in the range $y \in\left(y^{L T U}, y_{u b}\right)$, where $y_{u b}$ is the upper bound of the excluded region. The upper and lower bounds of the excluded interval, $\left(y_{l b}, y_{u b}\right)$ are also reported. Finally, $N$ is the number of observations included in the estimations, i.e. the number of firms with revenue $y \in(€ 3.01, € 9.01)$ million in each year. Significance levels: $* * *=1 \%, * *=5 \%$, and $*=10 \%$. 
Table 2: Sensitivity Analysis, Pooled 1999-2007 data

\begin{tabular}{|c|c|c|c|c|}
\hline \multicolumn{2}{|c|}{ "Excluded Interval } & \multicolumn{2}{|c|}{ Bunching Estimators } & \multirow{2}{*}{$\begin{array}{c}\text { Obs. } \\
N\end{array}$} \\
\hline$y_{l b}$ & $y_{u b}$ & $b_{a v}$ & $b_{r c}$ & \\
\hline 5.10 & 6.74 & $\begin{array}{c}0.095 \\
(0.019)^{* * *}\end{array}$ & $\begin{array}{c}0.560 \\
(0.201)^{* * *}\end{array}$ & 273,846 \\
\hline 5.20 & 6.78 & $\begin{array}{c}0.101 \\
(0.015)^{* * *}\end{array}$ & $\begin{array}{c}0.619 \\
(0.175)^{* * *}\end{array}$ & 273,846 \\
\hline 5.30 & 6.78 & $\begin{array}{c}0.101 \\
(0.012)^{* * *}\end{array}$ & $\begin{array}{c}0.620 \\
(0.134)^{* * *}\end{array}$ & 273,846 \\
\hline 5.40 & 6.74 & $\begin{array}{c}0.101 \\
(0.011)^{* * *} \\
\end{array}$ & $\begin{array}{c}0.593 \\
(0.122)^{* * *} \\
\end{array}$ & 273,846 \\
\hline 5.50 & 6.74 & $\begin{array}{c}0.101 \\
(0.009)^{* * *}\end{array}$ & $\begin{array}{c}0.567 \\
(0.095)^{* * *}\end{array}$ & 273,846 \\
\hline 5.60 & 6.62 & $\begin{array}{c}0.099 \\
(0.006)^{* * *}\end{array}$ & $\begin{array}{c}0.538 \\
(0.068)^{* * *}\end{array}$ & 273,846 \\
\hline 5.70 & 6.54 & $\begin{array}{c}0.098 \\
(0.005)^{* * *}\end{array}$ & $\begin{array}{c}0.487 \\
(0.054)^{* * *}\end{array}$ & 273,846 \\
\hline
\end{tabular}

Note: this table shows the sensitivity of the bunching estimators to different assumptions on the excluded region used to estimate the counterfactual. In all rows, we use the pooled 1999-2007 sample including all firms with reported revenue $y \in(€ 3.01, € 9.01)$. We pick different values of $y_{l b}$, as shown in the first column, and obtain the corresponding value of $y_{u b}$ and the point estimates for the bunching estimators $b_{a v}$ and $b_{r c}$ using the methods described in the main text. The results are very similar for all the reasonable choices of the lower bound $\left(y_{l b}\right)$, and we highlight the results for $y_{l b}=5.40$, which is the value chosen to produce the main estimation results. Significance levels: $* * *=1 \%,{ }^{*} *=5 \%$, and $*=10 \%$. 
Table 3: Heterogeneity of Bunching Response

\begin{tabular}{|c|c|c|c|c|c|c|c|}
\hline & \multicolumn{2}{|c|}{ Bunching Estimators } & \multicolumn{2}{|c|}{$\#$ of Firms } & \multicolumn{2}{|c|}{ Excl. Interval } & \multirow{2}{*}{$\begin{array}{c}\text { Obs. } \\
N\end{array}$} \\
\hline & $b_{a v}$ & $b_{r c}$ & $B$ & $H$ & $y_{l b}$ & $y_{u b}$ & \\
\hline \multicolumn{8}{|c|}{ By Sector of Activity } \\
\hline Building Contractors & $\begin{array}{c}0.148 \\
(0.031)^{* * *}\end{array}$ & $\begin{array}{c}0.524 \\
(0.200)^{* * *}\end{array}$ & 259 & 239 & 5.40 & 6.68 & 13,696 \\
\hline Construction & $\begin{array}{c}0.101 \\
(0.016)^{* * *}\end{array}$ & $\begin{array}{c}0.557 \\
(0.175)^{* *}\end{array}$ & 537 & 500 & 5.40 & 6.68 & 36,735 \\
\hline Manuf. Food \& Bev. & $\begin{array}{c}0.048 \\
(0.014)^{* * *}\end{array}$ & $\begin{array}{c}0.312 \\
(0.157)^{* *}\end{array}$ & 115 & 108 & 5.40 & 6.35 & 16,985 \\
\hline Manuf. Metals & $\begin{array}{c}0.107 \\
(0.022)^{* * *}\end{array}$ & $\begin{array}{c}0.605 \\
(0.313)^{* * *}\end{array}$ & 284 & 283 & 5.40 & 6.80 & 18,902 \\
\hline Manuf. Wood \& Paper & $\begin{array}{c}0.091 \\
(0.016)^{* * *}\end{array}$ & $\begin{array}{c}0.480 \\
(0.171)^{* * *}\end{array}$ & 343 & 312 & 5.40 & 6.56 & 25,991 \\
\hline Retail & $\begin{array}{c}0.076 \\
(0.017)^{* * *}\end{array}$ & $\begin{array}{c}0.384 \\
(0.154)^{* * *}\end{array}$ & 219 & 207 & 5.40 & 6.47 & 21,760 \\
\hline Restaurants \& Hotels & $\begin{array}{c}0.044 \\
(0.044)\end{array}$ & $\begin{array}{c}0.736 \\
(27.881)\end{array}$ & 40 & 42 & 5.40 & 7.04 & 6,960 \\
\hline Services & $\begin{array}{c}0.114 \\
(0.020)^{* * *}\end{array}$ & $\begin{array}{c}0.889 \\
(0.550)^{* *}\end{array}$ & 624 & 576 & 5.40 & 7.13 & 39,872 \\
\hline Wholesale & $\begin{array}{c}0.120 \\
(0.014)^{* * *}\end{array}$ & $\begin{array}{c}0.747 \\
(0.181)^{* * *}\end{array}$ & 1,390 & 1,260 & 5.40 & 6.89 & 78,853 \\
\hline Other & $\begin{array}{c}0.068 \\
(0.018)^{* * *}\end{array}$ & $\begin{array}{c}0.401 \\
(0.189)^{* * *}\end{array}$ & 134 & 127 & 5.40 & 6.47 & 14,084 \\
\hline \multicolumn{8}{|c|}{ By Number of Employees } \\
\hline Below median & $\begin{array}{c}0.111 \\
(0.013)^{* * *}\end{array}$ & $\begin{array}{c}0.538 \\
(0.119)^{* * *}\end{array}$ & 1,640 & 1,498 & 5.40 & 6.65 & 113,949 \\
\hline Above median & $\begin{array}{c}0.089 \\
(0.013)^{* * *}\end{array}$ & $\begin{array}{c}0.781 \\
(0.260)^{* * *}\end{array}$ & 1,588 & 1,453 & 5.40 & 6.92 & 113,720 \\
\hline \multicolumn{8}{|l|}{ By Fixed Assets } \\
\hline Below median & $\begin{array}{c}0.115 \\
(0.011)^{* * *}\end{array}$ & $\begin{array}{c}0.565 \\
(0.100)^{* * *}\end{array}$ & 1,999 & 1,850 & 5.40 & 6.74 & 137,325 \\
\hline Below median & $\begin{array}{c}0.089 \\
(0.012)^{* * *}\end{array}$ & $\begin{array}{c}0.614 \\
(0.164)^{* * *}\end{array}$ & 1,909 & 1,804 & 5.40 & 6.74 & 136,499 \\
\hline
\end{tabular}

Note: this table shows the bunching results across sectors of activity, by number of employees and by fixed assets. $b_{a v}$ is the average bunching response and $b_{r c}$ is the marginal buncher's response taking into account resource costs of evasion (both measured in million $€$ ). Bootstrapped standard errors are shown below each estimate in parenthesis. $B$ is the number of firms above the counterfactual density of revenue in the range $y \in\left(y_{l b}, y^{L T U}\right)$, where $y$ is revenue, $y_{l b}$ is the lower bound of the excluded region (used to construct the counterfactual) and $y^{L T U}$ is the LTU threshold of $€ 6$ million. $H$ is the missing number of firms below the counterfactual density in the range $y \in\left(y^{L T U}, y_{u b}\right)$, where $y_{u b}$ is the upper bound of the excluded region. The upper and lower bounds of the excluded interval, $\left(y_{l b}, y_{u b}\right)$ are also reported. $N$ is the number of observations included in each estimation. Significance levels: $* * *=1 \%, * *=5 \%$, and $*=10 \%$. 
Table 4: Bunching Persistence Over Time: Regression Results

\begin{tabular}{ccccccc}
\hline \hline & \multicolumn{5}{c}{ Dependent Variable: $\operatorname{Pr}\left[\right.$ bin $\left(y_{t}\right)=$ bin $\left.\left(y_{t+h}\right)\right]$} \\
\cline { 2 - 7 } & $h=1$ & $h=2$ & $h=3$ & $h=4$ & $h=5$ & $h=6$ \\
\hline BunchBin & 0.058 & 0.027 & 0.016 & 0.008 & 0.005 & 0.002 \\
& $(0.003)^{* * *}$ & $(0.003)^{* * *}$ & $(0.002)^{* * *}$ & $(0.002)^{* * *}$ & $(0.001)^{* * *}$ & $(0.001)^{* *}$ \\
& & & & & & \\
Constant & 0.207 & 0.147 & 0.122 & 0.103 & 0.091 & 0.082 \\
& $(0.003)^{* * *}$ & $(0.003)^{* * *}$ & $(0.003)^{* * *}$ & $(0.002)^{* * *}$ & $(0.002)^{* * *}$ & $(0.002)^{* * *}$ \\
\hline Obs. & 273,846 & 273,846 & 273,846 & 273,846 & 273,846 & 273,846 \\
Clusters & 75,946 & 75,946 & 75,946 & 75,946 & 75,946 & 75,946 \\
$R^{2}$ & 0.071 & 0.074 & 0.072 & 0.070 & 0.070 & 0.067 \\
\hline \hline
\end{tabular}

Note: this table reports coefficients from the following regression equation:

$$
\operatorname{Prob}\left[\operatorname{bin}\left(y_{i t}\right)=\operatorname{bin}\left(y_{i, t+h}\right)\right]=\alpha+\beta \text { BunchBin }_{i t}+y_{i t}+y_{i t}^{2}+\varepsilon_{i t},
$$

where $y_{i t}$ is reported revenue by firm $i$ in year $t$, the left-hand side variable is the fraction of firms that report revenues in the same bin in years $t$ and $t+h$, BunchBin $_{i t}$ takes value one if $y_{i t} \in(5.41,6.01]$. We add a quadratic polynomial in current reported revenue $\left(y_{i t}\right)$ as a way to control for the counterfactual probability that firms remain in a given revenue bin. Instead of using revenue levels, we use the distance to the notch so that the constant term $\alpha$ can be interpreted as the fraction of firms near the notch expected to remain at their current revenue level $h$ years later. 


\section{Online Appendix Not Intended for Publication}

"Heterogeneous Responses to Effective Tax
Enforcement: Evidence from Spanish Firms"

by Miguel Almunia (Warwick) and David Lopez-Rodriguez (Banco de España) 


\section{A Data: Further Details}

\section{Definition of Sectors of Activity}

The table below provides the 2- or 3-digit codes from the North-American Industry Classification System (NAICS, 2002) that we use to define sectors of activity in the empirical estimation. The middle column shows the number of firms in each sector for the pooled 1999-2007 dataset, and the percentage they represent overall.

\begin{tabular}{|c|c|c|c|c|}
\hline \multirow{2}{*}{$\frac{\text { Sector }}{\text { Construction }}$} & \multicolumn{2}{|l|}{ NAICS-2002 Codes } & \multicolumn{2}{|c|}{ \# of Firms } \\
\hline & \multicolumn{2}{|c|}{236 - Construction of buildings } & 36,735 & $(13.2 \%)$ \\
\hline Building Contractors & \multicolumn{2}{|c|}{238 - Specialty trade contractors } & 13,696 & $(5.0 \%)$ \\
\hline \multirow[t]{3}{*}{ Manufacturing } & \multicolumn{2}{|c|}{31 - Food and beverage products } & 16,985 & $(6.2 \%)$ \\
\hline & \multicolumn{2}{|c|}{32 - Wood, paper, chemical products } & 25,991 & $(9.5 \%)$ \\
\hline & \multicolumn{2}{|c|}{33 - Metal products, machinery } & 18,902 & $(6.9 \%)$ \\
\hline Wholesale & \multicolumn{2}{|l|}{42 - Wholesale trade } & 78,853 & $(28.8 \%)$ \\
\hline Retail & \multicolumn{2}{|l|}{$44 \& 45$ - Retail trade } & 21,760 & $(8.0 \%)$ \\
\hline Restaurants \& Hotels & \multicolumn{2}{|l|}{72 - Restaurants and hotels } & 6,960 & $(2.5 \%)$ \\
\hline \multirow[t]{5}{*}{ Services } & 48 - Transportation & 54 - Professional services & 39,872 & $(14.6 \%)$ \\
\hline & 49 - Postal \& warehousing & 55 - Management of firms & & \\
\hline & 51 - Information & 56 - Administrative support & & \\
\hline & 52 - Finance and insurance & 81 - Other services & & \\
\hline & 53 - Real estate & & & \\
\hline \multirow[t]{4}{*}{ Other } & 11 - Agriculture \& fishing & 61 - Education services & 14,084 & $(5.1 \%)$ \\
\hline & 21 - Mining & 62 - Health services & & \\
\hline & 22 - Utility companies & 71 - Arts and entertainment & & \\
\hline & 237 - Civil engineering & 92 - Public administration & & \\
\hline
\end{tabular}

Source: www.census.gov/cgi-bin/sssd/naics/naicsrch?chart=2002 


\section{Amadeus data and Final dataset}

To build the final dataset for this paper, we proceed as follows. In December 2011, we downloaded all the data available for Spanish firms in Amadeus, accessed online through Wharton Research Data Services (WRDS). This dataset is updated monthly and firms that have not reported information for 4 consecutive years are dropped, so it is possible that a subset firms that are included in our analysis are no longer in the online version of Amadeus. We include data for the years 1999 through 2007, both included.

In order to construct our final dataset for analysis, we take several steps. First, we drop observations from two regions where tax collection is independent of the federal tax authority and hence the LTU threshold does not apply (Pais Vasco and Navarra). Second, we choose a bin width of $€ 60,101$, which is one-hundredth of the revenue level of the LTU threshold. For symmetry, we keep 50 bins below and 50 bins above the threshold, so in total there are 100 bins. Hence, our final dataset has firms with reported revenue between $€ 3.005$ million and $€ 9.015$ million. Within this range, we define some of the ratios that we use in the section on input expenditures: materials and labor expenditures as $\%$ of revenue, average gross wages (defined as the total wage bill divided by the number of employees), and fixed assets as \% of revenue. Finally, we drop the top and bottom $1 \%$ of observations from each of these variables, in order to avoid the presence of outliers in the data. There is some overlap in the extreme values, such that a firm with abnormally high materials is likely to have abnormally low labor expenditures. The final dataset contains 273,846 observations, and summary statistics are reported on Table A.1. The Stata do-files used to process the original data to arrive at the final dataset are available upon request.

\section{Input-Output Tables}

We use the input-output tables produced by the National Statistics Institute (Instituto Nacional de Estadistica, INE) for the year 2000. Sectors of activity are defined according to Spanish industry classification, which does not match NAICS codes exactly but has substantial overlap. To calculate the share of sales made to final consumers by sector, we divide the column labelled "Consumo final de los hogares, interno" ("Households' final consumption, domestic") by the column "Total empleos" ("Total uses"). The original table used for the calculations can be downloaded from:

$$
\text { www.ine.es/daco/daco42/cne00/simetrica2000.xls }
$$

The table we provide together with our main dataset contains, additionally, the correspondence between our sector definitions (based on NAICS 2002 codes) and the sectors defined in the input-output tables. 


\section{B Expenditures Misreporting with Multiple Taxes}

Consider a firm that produces good $y$ combining material acquisitions $m$ and labor $n$, which are tax deductible expenditures ${ }^{39}$ in the corporate income tax, and non-deductible inputs $z$ according to the production function $y=\psi f(m, n, z)$, where $\psi$ is a productivity parameter and $f(\cdot, \cdot, \cdot)$ is strictly continuous, increasing and concave in inputs use. Firm hires in competitive markets materials at unit $\operatorname{cost} c$, labor at wage rate $w$, and nondeductible expenditures at unit cost $q$, and sell their output at the market price $p$, which is normalized to unity.

Suppose the existence of value added tax (VAT) by the credit method in which firms charge a flat tax rate $t^{v a t}$ on their sales $y$ and receive a credit for the monetary value of their material expenditures $e \equiv \mathrm{cm}$. Firms must transfer to the tax authority the difference between charged and deductible VAT, that is $t^{\text {vat }} \cdot P^{v a t}$ with $P^{v a t}=y-e$. Government also levies linear payroll taxes on the wage bill $P^{s s}=l \equiv w n$, charging $t^{s s_{1}}$ on account of employers, that are tax deductible in the corporate income tax, and $t^{s s_{2}}$ on account of employers. We assume that both payroll taxes are fully born by firms. Firms also consider the regulatory costs associated to hiring labor captured by a convex cost function in the reported wage bill, $\gamma(l) .{ }^{40}$ Finally, the income generated by the firm is taxed with a proportional rate $t^{c i t}$ on taxable profits $P^{c i t}=y-e-l \cdot\left(1+t^{s s_{1}}\right)$, so firm's net-of-tax income with truthful reporting is given by $\Pi=\left(1-t^{c i t}\right) P^{c i t}-P^{s s} t^{s s_{2}}-q z-\gamma(l)$.

Suppose that the tax authority is not able to monitor all transactions in the economy creating incentives for firms to evade taxes by misreporting their tax bases. Consider that an evader firm could underreport the monetary value of their revenue by an amount $u^{y} \equiv y-\bar{y} \geq 0$, where $\bar{y}$ denotes reported revenue, to reduce taxable corporate income and to appropriate tax revenue from the VAT. Firm may also attempt to inflate the value of their material acquisitions, given by $u^{e} \equiv \bar{e}-e \geq 0$, where $\bar{e}$ denotes reported expenditures, to claim larger tax credits in both corporate income tax and the VAT. Firms may have incentives to hide a share of their wage bill by an amount $u^{l} \equiv l-\bar{l} \geq 0$, where $\bar{l}$ denotes reported labor expenditures, to evade payroll taxes and save regulatory costs of hiring labor. Given these potential evasion channels, firm's reported tax bases in

\footnotetext{
${ }^{39}$ We make the distinction between this two tax-deductible inputs because the dataset in our empirical application includes accurate measures of firms' total expenditures on material acquisitions and labor wage bill.

${ }^{40}$ The assumptions on the incidence of payroll taxes on account of employers and employees, and the existence of regulatory costs associated to hiring workers seems particularly appropriate for the Spanish case. As an example, Alvaredo and Saez (2013) provide suggestive empirical evidence on the incidence of the Spanish payroll taxes on firms; and Bentolila, Dolado and Jimeno (2008) discuss the costs and rigidities imposed on Spanish firms by multiple regulations in labor markets.
} 
the corporate income tax, payroll taxes and the VAT are given, respectively, by

$$
\begin{gathered}
\overline{P^{c i t}}=\left[\left(y-u^{y}\right)-\left(e+u^{e}\right)-\left(l-u^{l}\right) \cdot\left(1+t^{s s_{1}}\right)\right], \\
\overline{P^{s s}}=\left(l-u^{l}\right), \\
\text { and } \overline{P^{v a t}}=\left[\left(y-u^{y}\right)-\left(e+u^{e}\right)\right] .
\end{gathered}
$$

Evasion behavior is costly because it requires, for instance, collusion between the firm and its trading partners and employees; the creation of parallel accounting books and payment systems in cash; or it can imply forego business opportunities. We introduce these resource costs of evasion by a reduced form $\kappa\left(u^{y}, u^{e}, u^{l}\right)$ that is an increasing, convex and separable function in each of its arguments. The tax authority detects evasion with probability $\delta=\phi h\left(u^{y}, u^{e}, u^{l}\right)$, where $\phi$ is the enforcement intensity parameter and $h(\cdot)$ is a continuos, convex and separable function in each evasion channel. Whenever misreporting is detected, the firm is compelled to pay back the evaded tax plus a proportional penalty rate $\theta$ that, for simplicity, is assumed homogeneous for all channels of evasion.

The expected profit of the firm net of corporate and payroll taxes, and augmented by the expected appropriation of VAT revenue, is given by

$$
\begin{aligned}
E \Pi= & \left(1-t^{c i t}\right)\left[\psi f(m, n, z)-e-l\left(1+t^{s s_{1}}\right)\right]-q z+t r \cdot\left[u^{y}+u^{e}-u^{l}\left(1+t^{s s_{1}}\right)\right] \\
& +\left(t^{s s_{1}}+t^{s s_{2}}\right) \cdot r u^{l}+t^{v a t} \cdot r\left[u^{y}+u^{e}\right]-\kappa\left(u^{y}, u^{e}, u^{l}\right)-\gamma(\bar{l}),
\end{aligned}
$$

where $r \equiv\left[1-\phi h\left(u^{y}, u^{e}, u^{l}\right)(1+\theta)\right]$ is the expected rate of return of 1 euro evaded. Firms make production and reporting decisions in order to maximize their expected profit such that an interior optimum for firms real and evasion decisions satisfies the system of firstorder conditions given by

$$
\begin{gathered}
\psi f_{m}\left(m^{*}, n^{*}, z^{*}\right)=c \\
\psi f_{n}\left(m^{*}, n^{*}, z^{*}\right)=w\left[1+t^{s s_{1}}+\frac{t^{s s_{2}}+\gamma \bar{l}\left(\bar{l}^{*}\right)}{\left(1-t^{c i t}\right)}\right] \\
\psi f_{z}\left(m^{*}, n^{*}, z^{*}\right)=q /(1-t) \\
{\left[t^{c i t}+t^{v a t}\right] \cdot r=\kappa_{u^{y}}\left(u^{y *}\right)+(1+\theta) \phi h_{u^{y}}\left(u^{y *}\right) \cdot \widehat{T}} \\
{\left[t^{c i t}+t^{v a t}\right] \cdot r=\kappa_{u^{e}}\left(u^{e *}\right)+(1+\theta) \phi h_{u^{e}}\left(u^{e *}\right) \cdot \widehat{T}} \\
{\left[\left(t^{s s_{1}}+t^{s s_{2}}\right)-t^{c i t}\left(1+t^{s s_{1}}\right)\right] \cdot r+\gamma \bar{l}\left(\bar{l}^{*}\right)=\kappa_{u^{l}}\left(u^{l *}\right)+(1+\theta) \phi h_{u^{l}}\left(u^{l *}\right) \cdot \widehat{T}}
\end{gathered}
$$

where $\widehat{T} \equiv\left[t^{v a t} \cdot\left(u^{y *}+u^{e *}\right)+\left(t^{s s_{1}}+t^{s s_{2}}\right) \cdot u^{l *}+t^{c i t} \cdot\left(u^{y *}+u^{e *}-u^{l *}\left(1+t^{s s_{1}}\right)\right)\right]$ is the total evaded 
taxes by the multiple misreporting channels. The system of optimal conditions shows that positive tax rates on corporate income distort inputs demand decisions reducing revenue from potential production at zero tax rates. These conditions also indicate that the existence of both payroll taxes and labor regulatory costs create distortions increasing the marginal cost of hiring employees and thus reducing labor demand.

The optimal evasion conditions for each misreporting channel predict that firm evades taxes to the point where the marginal expected return of misreporting transactions is equal to the expected costs associated to tax evasion. The latter is the result of the marginal resource costs born in each misreporting channel plus the deterrence effect created by tax enforcement that results from the interaction between monitoring effort and the existence of paper trail. The systematic matching of tax returns from multiple taxpayers implies that a marginal unit of misreporting in one channel increases the chances of being detected, and thus paying back the total amount evaded, in multiple channels.

The expected returns of misreporting revenue and expenditures are positively related with the tax rates. The larger the tax rates on both the VAT and the corporate income tax are, the higher the incentives to hide revenue and inflate material acquisitions to reduce

those tax bases. Notice that when firms have scope to misreport their transactions they do not act as fiscal intermediaries, that just transfer collected VAT to the tax agency, but instead firms have incentives to appropriate a share of VAT revenue. Finally, the optimal condition for hidden labor bill indicates that firms could have incentives to misreport it when the marginal savings in payroll taxes and regulatory costs were larger than the foregoing tax credits in corporate income tax due misreporting of labor costs. Overall, the model identifies two channels that create positive returns for labor misreporting: i) the existence of a significant gap between payroll taxes and corporate tax rates; and ii) the presence of large regulatory costs associated to hiring workers.

\section{B.1 Anatomy of the Response: Input Ratios at the LTU Thresh- old}

Consider the extended model with heterogeneous enforcement intensities and resource costs presented in section 2. Before the introduction of a LTU, the system of optimal conditions indicates that the demand of tax-deductible inputs (e.g. materials and labor) is smoothly increasing in productivity, $d m / d \psi>0$ and $d n / d \psi>0$. Hence, the reported ratios of input expenditures over revenue, $\bar{M} \equiv c m / \bar{y}$ and $\bar{L} \equiv w n / \bar{y}$, are continuous in $\psi$ over the range $[\underline{\psi}, \bar{\psi}]$. This implies that in the neighborhood of $y^{L}$ defined by the small interval $\left(y^{\prime}, y^{L}+d \bar{y}_{\phi}^{M}\right)$ the average reported ratios of inputs expenditures over revenue 
are almost equal, that is,

$$
\frac{\int_{y^{\prime}}^{y^{L}} \bar{M} \cdot g_{0}(\bar{y}) d \bar{y}}{\int_{y^{\prime}}^{y^{L}} g_{0}(\bar{y}) d \bar{y}} \cong \frac{\int_{y^{L}}^{y^{L}+d \bar{y}_{\phi}^{M}} \bar{M} \cdot g_{0}(\bar{y}) d \bar{y}}{\int_{y^{L}}^{y^{L}+d \bar{y}_{\phi}^{M}} g_{0}(\bar{y}) d \bar{y}} \quad \text { and } \quad \frac{\int_{y^{\prime}}^{y^{L}} \bar{L} \cdot g_{0}(\bar{y}) d \bar{y}}{\int_{y^{\prime}}^{y^{L}} g_{0}(\bar{y}) d \bar{y}} \cong \frac{\int_{y^{L}}^{y^{L}+d \bar{y}_{\phi}^{M}} \bar{L} \cdot g_{0}(\bar{y}) d \bar{y}}{\int_{y^{L}}^{y^{L}+d \bar{y}_{\phi}^{M}} g_{0}(\bar{y}) d \bar{y}}
$$

Suppose the LTU is introduced. In the presence of resource costs we assume that there is a constant proportion of firms $\alpha$ with prohibitive resource costs to react in the pre-LTU density interval (defined) by $\left(y^{L}, y^{L}+d \bar{y}_{\phi}^{M}\right)$. In contrast, there is a proportion $1-\alpha$ of firms in this interval, the bunchers, that reduce their reported revenue to stay below the threshold when that results in larger expected profits, i.e. $E \Pi_{0}(m, n, z, u \mid$ $\left.\psi^{M}, \phi_{0}\right)>E \Pi_{1}\left(m, n, z, u \mid \psi^{M}, \phi_{1}\right)$. Assuming that the bunchers locate in the interval $\left(y^{\prime}, y^{L}\right)$, we obtain different predictions on the expected average reported ratios of input expenditures over revenue around the LTU threshold depending on whether these firms' reaction is due real (i.e. reduction of production) or evasion (i.e. increase of concealed revenue) adjustments. ${ }^{41}$

Real Response. Bunchers can react to the threshold lowering their production, and thus their inputs demand, without bearing additional resource costs of evasion. This reaction yields that in the interval $\left(y^{\prime}, y^{L}\right)$ below the threshold there are firms with $\psi \in$ $\left[\psi^{\prime}, \psi^{L}\right]$ that hire more inputs than bunchers with $\psi \in\left[\psi^{L}, \psi^{M}\right]$. This causes that both average reported ratios of expenditures over revenue are not continuous at the threshold $y^{L}$. The reaction of the bunchers to the LTU yields a (discrete) upward jump of these ratios at the threshold such that

$$
\frac{\int_{y^{\prime}}^{y^{L}} \bar{M} \cdot g_{1}(\bar{y}) d \bar{y}}{\int_{y^{\prime}}^{y^{L}} g_{1}(\bar{y}) d \bar{y}}<\frac{\int_{y^{L}}^{y^{L}+d \bar{y}_{\phi}^{M}} \bar{M} \cdot g_{1}(\bar{y}) d \bar{y}}{\int_{y^{L}}^{y^{L}+d \bar{y}_{\phi}^{M}} g_{1}(\bar{y}) d \bar{y}} \quad \text { and } \quad \frac{\int_{y^{\prime}}^{y^{L}} \bar{L} \cdot g_{1}(\bar{y}) d \bar{y}}{\int_{y^{\prime}}^{y^{L}} g_{1}(\bar{y}) d \bar{y}}<\frac{\int_{y^{L}}^{y^{L}+d \bar{y}_{\phi}^{M}} \bar{L} \cdot g_{1}(\bar{y}) d \bar{y}}{\int_{y^{L}}^{y^{L}+d \bar{y}_{\phi}^{M}} g_{1}(\bar{y}) d \bar{y}} \text {. }
$$

Evasion Response. Bunchers can react to the threshold increasing their concealed revenue, and thus without modifying their inputs demand, paying resource costs of additional evasion. This response implies that in the interval $\left(y^{\prime}, y^{L}\right)$ below the threshold firms with $\psi \in\left[\psi^{\prime}, \psi^{L}\right]$ hire lower inputs than bunchers with $\psi \in\left[\psi^{L}, \psi^{M}\right]$. The response of the bunchers thus creates a discontinuity in the average reported ratios of expenditures at the threshold $y^{L}$ with a (discrete) downward jump of these ratios at the threshold such

\footnotetext{
${ }^{41}$ The bunchers' reaction to the LTU threshold could be a combination of both potential responses, real and evasion, but we discuss the two polar responses for analytical simplicity. This simplification provides predictions on the expected average patterns of input ratios around the threshold when the reaction is dominated by either the real or the evasion channel.
} 
that

$$
\frac{\int_{y^{\prime}}^{y^{L}} \bar{M} \cdot g_{1}(\bar{y}) d \bar{y}}{\int_{y^{\prime}}^{y^{L}} g_{1}(\bar{y}) d \bar{y}}>\frac{\int_{y^{L}}^{y^{L}+d \bar{y}_{\phi}^{M}} \bar{M} \cdot g_{1}(\bar{y}) d \bar{y}}{\int_{y^{L}}^{y^{L}+d \bar{y}_{\phi}^{M}} g_{1}(\bar{y}) d \bar{y}} \quad \text { and } \quad \frac{\int_{y^{\prime}}^{y^{L}} \bar{L} \cdot g_{1}(\bar{y}) d \bar{y}}{\int_{y^{\prime}}^{y^{L}} g_{1}(\bar{y}) d \bar{y}}>\frac{\int_{y^{L}}^{y^{L}+d \bar{y}_{\phi}^{M}} \bar{L} \cdot g_{1}(\bar{y}) d \bar{y}}{\int_{y^{L}}^{y^{L}+d \bar{y}_{\phi}^{M}} g_{1}(\bar{y}) d \bar{y}} \text {. }
$$

Evasion Response with Inputs Misreporting. Firms that react to the LTU threshold to avoid stricter tax enforcement can have larger incentives to bunch when they also evade taxes by misreporting their expenditures. Considering the extended model with inputs misreporting and multiple taxes presented above (or in section A.1), evader firms have incentives to inflate their materials acquisitions in an amount $u^{e}$ to claim larger tax credits in both the VAT and the CIT; and they have incentives to hide their wage bill in an amount $u^{l}$ to save high payroll taxes and the regulatory costs of hiring labor. In this case, the ratios of reported input expenditures over revenue for evader firms are given by $\bar{M} \equiv\left(c m+u^{e}\right) / \bar{y}$ and $\bar{L} \equiv\left(w n-u^{l}\right) / \bar{y}$, respectively. When evaders react to the LTU threshold increasing their concealed revenue, they hire more inputs than firms with $\psi \in\left[\psi^{\prime}, \psi^{L}\right]$ that are also located in the interval $\left(y^{\prime}, y^{L}\right)$, and they report higher (lower) materials (labor) expenditures to evade taxes. The response of bunchers that misreport their inputs expenditures to evade taxes creates a downward (upward) jump of the ratio of materials (labor) at the threshold such that

$\frac{\int_{y^{\prime}}^{y^{L}} \bar{M} \cdot g_{1}(\bar{y}) d \bar{y}}{\int_{y^{\prime}}^{y^{L}} g_{1}(\bar{y}) d \bar{y}}>>\frac{\int_{y^{L}}^{y^{L}+d \bar{y}_{\phi}^{M}} \bar{M} \cdot g_{1}(\bar{y}) d \bar{y}}{\int_{y^{L}}^{y^{L}+d \bar{y}_{\phi}^{M}} g_{1}(\bar{y}) d \bar{y}} \quad$ and $\quad \frac{\int_{y^{\prime}}^{y^{L}} \bar{L} \cdot g_{1}(\bar{y}) d \bar{y}}{\int_{y^{\prime}}^{y^{L}} g_{1}(\bar{y}) d \bar{y}}<\frac{\int_{y^{L}}^{y^{L}+d \bar{y}_{\phi}^{M}} \bar{L} \cdot g_{1}(\bar{y}) d \bar{y}}{\int_{y^{L}}^{y^{L}+d \bar{y}_{\phi}^{M}} g_{1}(\bar{y}) d \bar{y}}$ 


\section{Appendix Tables}

Table A.1: Summary Statistics

\begin{tabular}{lcccccc}
\hline \hline & Mean & Std. Dev. & Median & Min. & Max. & Obs. \\
\hline Operating Revenue (million $€$ ) & 4.89 & 1.54 & 4.48 & 3.01 & 9.01 & 273,846 \\
Fixed Assets (million $€$ ) & 1.34 & 2.56 & 0.57 & 0.00 & 42.75 & 273,824 \\
Material Expenditures (million $€$ ) & 3.17 & 1.55 & 2.98 & 0.02 & 8.94 & 269,299 \\
Labor Expenditures (million $€$ ) & 0.76 & 0.71 & 0.56 & 0.01 & 7.08 & 267,295 \\
Materials as \% of Revenue & $64.7 \%$ & $22.6 \%$ & $69.5 \%$ & $0.8 \%$ & $99.8 \%$ & 269,299 \\
Labor as \% of Revenue & $15.8 \%$ & $13.4 \%$ & $12.1 \%$ & $0.4 \%$ & $80.3 \%$ & 267,295 \\
Average Gross Wage (€) & 27,768 & 13,322 & 24,802 & 7,977 & 135,217 & 231,713 \\
Number of Employees & 31.2 & 31.9 & 23 & 1 & 756 & 231,804 \\
\hline \hline
\end{tabular}

Note: this table shows summary statistics for firms in the final dataset used for analysis, which is restricted to firms with reported revenue $y \in(€ 3.01, € 9.01)$ million. The top and bottom $1 \%$ of the variables "Materials as \% of revenue", "Labor as \% of revenue", "Fixed assets as \% of revenue" and "Average gross wage" were dropped from the initial dataset to prevent outliers (and potentially incorrect data entries) from biasing the empirical estimations. The number of observations is different for each variable due to missing values, an issue especially relevant for the number of employees variable, which is not reported by about $20 \%$ of the firms.

Source: annual data from Amadeus (published by Bureau van Dijk) for Spanish firms in the period 1999-2007. More details about the data are given in section A in the online appendix. 
Table A.2: Revenue Threshold: Corporate Income Tax Benefit for Small Firms

\begin{tabular}{|c|c|c|c|c|}
\hline Year & Threshold & Standard tax rate & Special tax rate & Applicable range \\
\hline $\begin{array}{l}1999 \\
2000\end{array}$ & $€ 1.5$ million & \multirow{6}{*}{$35 \%$} & \multirow{6}{*}{$30 \%$} & Un to \\
\hline 2001 & $€ 3$ million & & & $€ 90,151$ \\
\hline $\begin{array}{l}2002 \\
2003\end{array}$ & $€ 5$ million & & & $\begin{array}{c}\text { of taxable } \\
\text { profits }\end{array}$ \\
\hline 2004 & $€ 6$ million & & & \\
\hline 2005 & \multirow{5}{*}{$€ 8$ million } & & & Up to \\
\hline 2006 & & & & $€ 120,202$ \\
\hline 2007 & & $32.5 \%$ & & of taxable \\
\hline 2008 & & \multirow{5}{*}{$30 \%$} & \multirow{5}{*}{$25 \%$} & profits \\
\hline 2009 & & & & \\
\hline 2010 & & & & Up to \\
\hline 2011 & $€ 10$ million & & & $€ 300,000$ \\
\hline 2012 & & & & of tax. profits \\
\hline
\end{tabular}

Source: the applicable laws are: Law 43/1995 (Article 122), Law 6/2000 (Article 122), Law 24/2001 (Article 122), Law 4/2004 (Article 108), Law 2/2004 of the Presupuestos Generales del Estado (Annual Government Budget Law, Article 108), and Real Decreto Ley 13/2010 (Royal Law Decree, Article 108).

Table A.3: Overview of the Spanish Tax System

\begin{tabular}{lcc} 
& Top tax rate & Share of tax revenue \\
\hline \hline Social Security Contributions (SSC) & $38 \%$ & $33 \%$ \\
Individual Income Tax (IIT) & $48 \%(46 \%)$ & $22 \%$ \\
Value-Added Tax (VAT) & $16 \%$ & $19 \%$ \\
Corporate Income Tax (CIT) & $35 \%(30 \%)$ & $13 \%$ \\
Other indirect taxes and fees & - & $13 \%$ \\
\hline Federal Tax Revenue / GDP & \multicolumn{2}{c}{$30-37 \%$} \\
\hline \hline
\end{tabular}

Sources: Instituto de Estudios Fiscales (IEF, 2011). The top marginal rate of the individual income tax was reduced to $46 \% 2005$. The top marginal rate of the corporate income tax was reduced to $32.5 \%$ in 2006 and $30 \%$ in 2007 . The data on tax revenues reflects averages for the period 1999-2007 and include regional-level revenues in all calculations. 
Table A.4: Amadeus Dataset Compared to Official Statistics

\begin{tabular}{|c|c|c|c|c|c|c|c|c|c|}
\hline & & \multicolumn{2}{|c|}{ All Firms } & \multicolumn{2}{|c|}{ 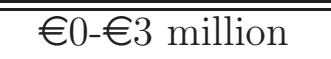 } & \multicolumn{2}{|c|}{ ¿€3-€10 million } & \multicolumn{2}{|c|}{ "€10+ million } \\
\hline \multirow{2}{*}{1999} & Official & 792,973 & & 752,698 & & 28,476 & & 10,798 & \\
\hline & Amadeus & 250,385 & $31.6 \%$ & 218,429 & $290.0 \%$ & 23,144 & $81.3 \%$ & 8,812 & $81.6 \%$ \\
\hline \multirow{2}{*}{2000} & Official & 876,530 & & 828,082 & & 34,014 & & 14,433 & \\
\hline & Amadeus & 286,837 & $32.7 \%$ & 249,401 & $30.1 \%$ & 26,688 & $78.5 \%$ & 10,748 & $74.5 \%$ \\
\hline \multirow{2}{*}{2001} & Official & 928,897 & & 874,992 & & 37,382 & & 16,523 & \\
\hline & Amadeus & 370,174 & $39.9 \%$ & 328,040 & $37.5 \%$ & 29,885 & $79.9 \%$ & 12,249 & $74.1 \%$ \\
\hline \multirow{2}{*}{2002} & Official & $1,008,744$ & & 951,152 & & 40,388 & & 17,204 & \\
\hline & Amadeus & 444,215 & $440.0 \%$ & 398,015 & $41.8 \%$ & 32,887 & $81.4 \%$ & 13,312 & $77.4 \%$ \\
\hline \multirow{2}{*}{2003} & Official & $1,041,527$ & & 979,918 & & 43,246 & & 18,363 & \\
\hline & Amadeus & 488,076 & $46.9 \%$ & 437,670 & $44.7 \%$ & 35,730 & $82.6 \%$ & 14,676 & $79.9 \%$ \\
\hline \multirow{2}{*}{2004} & Official & $1,117,005$ & & $1,050,143$ & & 46,806 & & 20,056 & \\
\hline & Amadeus & 523,405 & $46.9 \%$ & 468,128 & $44.6 \%$ & 39,023 & $83.4 \%$ & 16,252 & $810.0 \%$ \\
\hline \multirow{2}{*}{2005} & Official & $1,200,267$ & & $1,126,588$ & & 51,062 & & 22,617 & \\
\hline & Amadeus & 583,992 & $48.7 \%$ & 522,679 & $46.4 \%$ & 43,139 & $84.5 \%$ & 18.168 & $80.3 \%$ \\
\hline \multirow{2}{*}{2006} & Official & $1,293,419$ & & $1,210,736$ & & 56,952 & & 25,731 & \\
\hline & Amadeus & 664,679 & $51.4 \%$ & 594,443 & $49.1 \%$ & 49,265 & $86.5 \%$ & 20,966 & $81.5 \%$ \\
\hline \multirow{2}{*}{2007} & Official & $1,410,188$ & & $1,321,500$ & & 60,699 & & 27,989 & \\
\hline & Amadeus & 610,974 & $43.3 \%$ & 539,977 & $40.9 \%$ & 49,148 & $810.0 \%$ & 21,843 & $780.0 \%$ \\
\hline
\end{tabular}

Note: The percentages indicate the proportion of firms with complete revenue data in Amadeus compared to the number of firms that submitted a corporate income tax return that year. Official statistics are from several issues of "Memoria de Administración Tributaria", an annual report published by the Spanish tax agency (AEAT, 1999-2008). The Amadeus dataset is described in detail in section 4 . 


\section{Appendix Figures}

Figure A.1: Behavioral (Non)response at the Corporate Income Tax Threshold
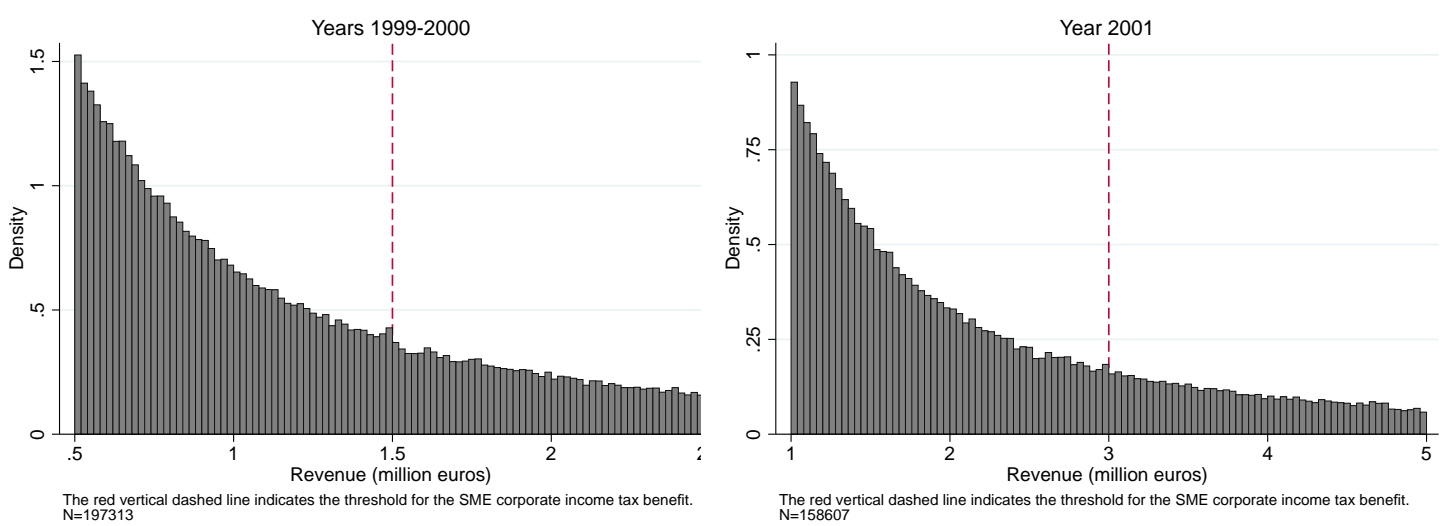

The red vertical dashed line indicates the threshold for the SME corporate income tax benefil
$\mathrm{N}=158607$
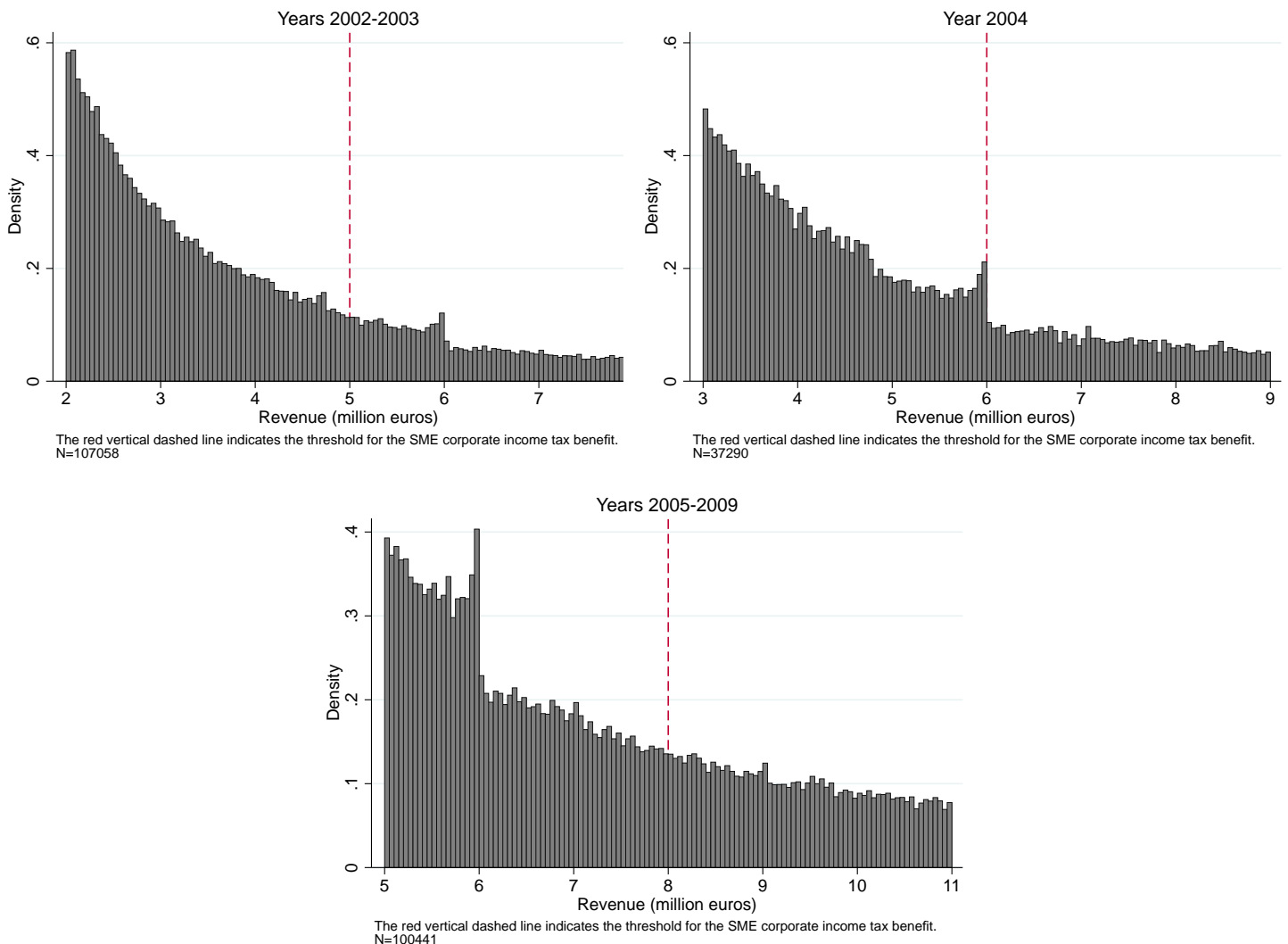

Note: these graphs show the operating revenue distribution for different periods, around the threshold for the corporate income tax cut for small firms. There is no bunching at this threshold in any year except for 2004, the year in which this cutoff overlapped with the LTU threshold discussed in the main text. 





Figure A.3: Revenue Distribution by Organizational Form
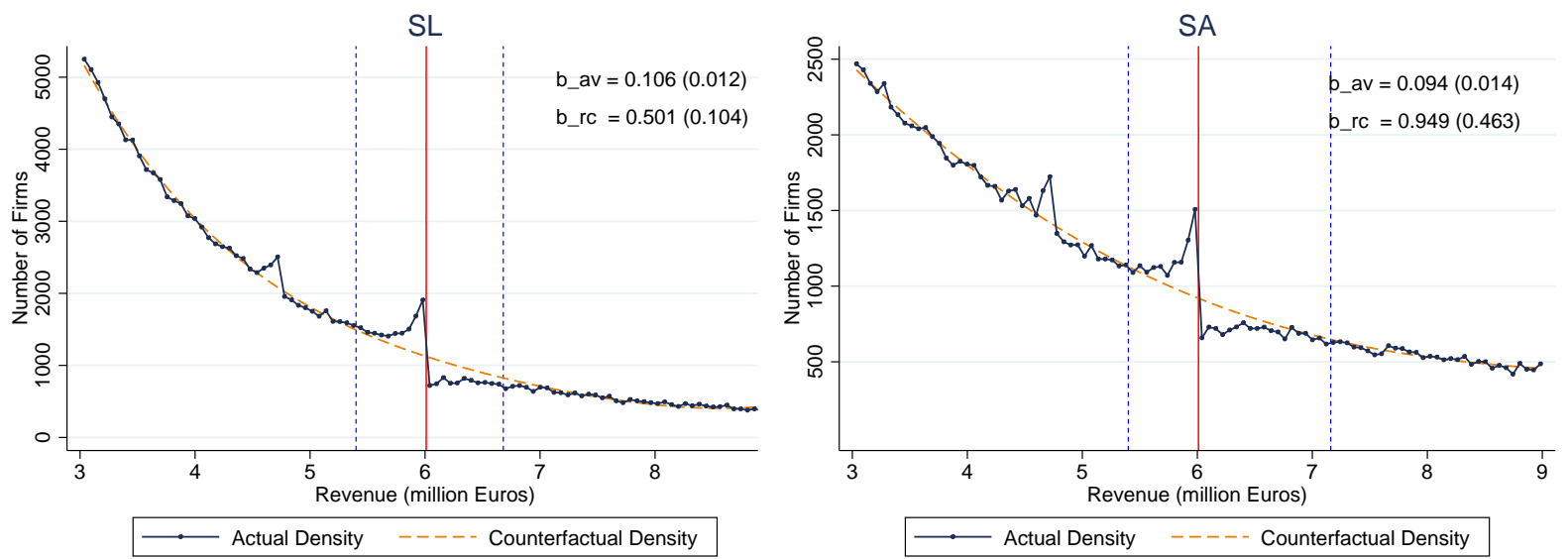

Note: these graphs show the actual and counterfactual revenue distributions for firms with different organizational forms. SL stands for Sociedad Limited, equivalent to a Limited Liability Company. SA stands for Sociedad Anónima, equivalent to a Corporation. The counterfactual distribution is constructed in each case as explained in the note to Figure 3. 